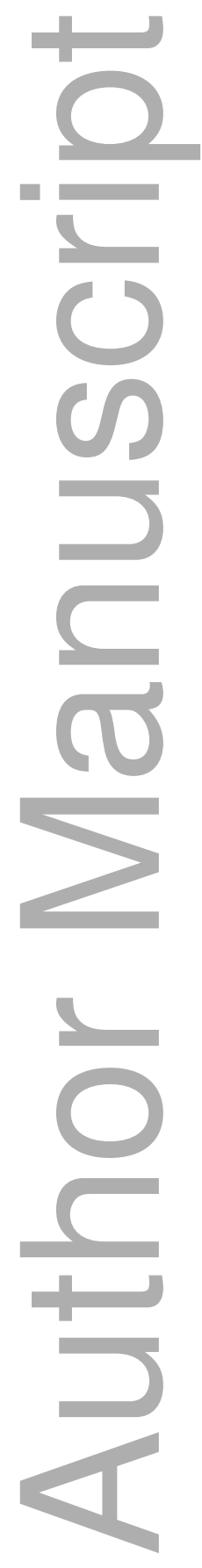

This is the author manuscript accepted for publication and has undergone full peer review but has not been through the copyediting, typesetting, pagination and proofreading process, which may lead to differences between this version and the Version of Record. Please cite this article as doi: $\underline{10.1111 / 1475-4932.12506}$

This article is protected by copyright. All rights reserved 


\section{Once in a Lifetime? The Effects of the Global Financial Crisis on Household Willingness to take Financial Risk*}

$-$

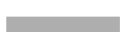

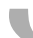

$(3)$

0

We in

We investigate the effect of the Global Financial Crisis (GFC) on household willingness to take risk. A model incorporating experienced returns as a determinant of risk tolerance is specified, with time varying weights on past stock returns capturing changes during the crisis. Results show households became more myopic during the GFC, placing greater weight on more recent stock returns when evaluating financial risk attitudes. Households have been more sensitive to financial shocks during the GFC and post-GFC periods, with the change in sensitivity found to be uniform over the life cycle and other household characteristics, but differing by income.

Keywords: Risk Taking; Global Financial Crisis; Experienced Returns; Life Cycle Effects.

JEL Classification: G01, D14, E21, D80

*We thank the editor and two anonymous referees for helpful comments and suggestions. We are also grateful to Chris Ryan, Cain Polidano, Bruce Preston, Sandy Suardi, Joe Vecci and Roger Wilkins for helpful discussions, comments and suggestions. Financial support from the La Trobe Business School internal research grant scheme (IRGS) is gratefully acknowledged. We thank Richard McAllister for excellent research assistance with the data. Part of this research was undertaken while Cardak was visiting the MIAESR at the University of Melbourne, he gratefully acknowledges their hospitality. This paper uses unit record data from the Household, Income and Labour Dynamics in Australia (HILDA) Survey. The HILDA Project was initiated and is funded by the Australian Government Department of Families, Housing, Community Services and Indigenous Affairs (FaHCSIA) and is managed by the Melbourne Institute of Applied Economic and Social Research (MIAESR). The findings and views reported in this paper are those of the authors and should not be attributed to FaHCSIA or the MIAESR.

†Department of Economics and Finance, La Trobe University, Bundoora 3086, Victoria, Australia. Email: b.cardak@latrobe.edu.au

${ }^{\ddagger}$ Department of Economics, University of Melbourne, Parkville 3010, Victoria, Australia. Email: vance@unimelb.edu.au 


\title{
Once in a Lifetime? The Effects of the Global Financial Crisis on Household Willingness to take Financial Risk
}

\author{
September 2019
}

\begin{abstract}
We investigate the effect of the Global Financial Crisis (GFC) on household willingness to take risk. A model incorporating experienced returns as a determinant of risk tolerance is specified, with time varying weights on past stock returns capturing changes during the crisis. Results show households became more myopic during the GFC, placing greater weight on more recent stock returns when evaluating financial risk attitudes. Households have been more sensitive to financial shocks during the GFC and post-GFC periods, with the change in sensitivity found to be uniform over the life cycle and other household characteristics, but differing by income.
\end{abstract}
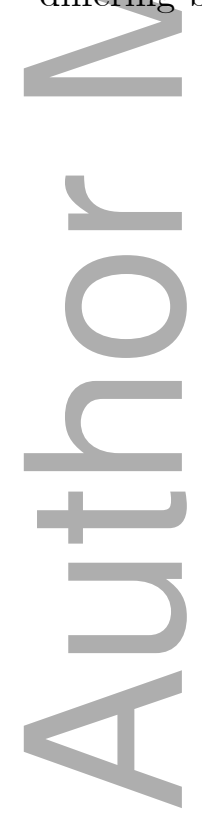


\section{Introduction}

Over the last decade stock markets have experienced a series of extreme events with one of the worst being the global financial crisis (GFC) beginning in 2008, which, in turn, triggered the Great Recession resulting in the largest economic downturn since the Great Depression in the 1930s (IMF (2009)). Some of the biggest declines experienced in financial markets occurred in early October 2008, with the U.S. stock market declining by more than $18 \%$ and resulting in financial market collapses across the globe, including Australia, where equity values declined by a similar amount (Bloomberg (2008)). The GFC resulted in monetary policy responses including low interest rates and quantitative easing, in place for nearly a decade. How households reacted to these "once in a lifetime" events has important economic and financial implications as a reduced willingness to take risk can decrease the availability of resources for capital formation and impede economic growth, thereby harming economic welfare. ${ }^{2}$

The aim of this paper is to study how households adjusted their attitudes towards taking financial risks in response to the extreme events of the GFC by using panel data from the nationally representative Household Income and Labour Dynamics in Australia (HLLDA) longitudinal survey from 2001 to 2015. This is achieved by specifying a model of the willingness to take financial risk as a function of a weighted average of past stock market returns over the life of a household, referred to as experienced returns (Malmendier and Nagel (2011) and Ampudia and Ehrmann (2017)). In contrast to previous literature which uses a constant weighting scheme, a more flexible model is specified by allowing for time-varying weights to capture changes in risk taking behaviour arising during the GFC and post-GFC periods. This approach uses a polynomial structure that links the weighting parameters over the period of the crisis. This choice of specification improves the precision and ensures identification of the time varying weighting parameters of the model by reducing the number of unknown parameters that need to be estimated. An important feature of the proposed model is that the

\footnotetext{
${ }^{1}$ The impact of the GFC on the Australian economy and households has been studied by Dungey et al. (2017).

${ }^{2}$ Brown et al. (2013) show that across a wide range of countries stock market financing is of critical importance to R\&D investment, as intangible ideas, unless patented, cannot serve as security for debt. The innovations that flow from $\mathrm{R} \& \mathrm{D}$ activities and drive economic growth are therefore reliant on the willingness of households to take financial risk by providing equity investment either directly through stocks or indirectly through managers of equity funds.
} 
fixed weighting parameter specification of Malmendier and Nagel (2011) is adopted for the pre-GFC period, thereby providing an appropriate benchmark for evaluating changes in the experienced returns weights during the GFC and post-GFC periods.

An allowance for changes in risk taking behaviour over time represents an important area of research in finance. Previous work beginning with Campbell and Cochrane (1999) allows for time-varying relative risk aversion by including habit persistence in the consumption capital asset pricing model. Brunnermeier and Nagel (2008) adopt a similar approach, but use micro-level data instead to estimate the model. In related work, Bekaert and Hoerova (2016) develop a model to distinguish between risk aversion and uncertainty and show how these terms connect with commonly used financial measures of stress. An alternative line of research by Bali and Engle (2010) and Engle et al. (2013) allows for time variations in risk by conditioning on past information through the specification of dynamic variance and covariance equations. There is also a growing literature in behavioral finance by Cohn et al. (2015) and Kandasamy et al. (2014) amongst others showing that individual preferences may not be stable when subjected to extreme events. Empirical applications of this approach to the GFC are given by Hoffmann et al. (2013), Weber et al. (2013) and Merkle and Weber (2014), while Guiso et al. (2018) build on the literature by combining empirical and behavioural approaches.

The empirical results presented in this paper provide strong evidence that households became more myopic during the GFC by increasing their focus on more recent stock market returns, although past returns nonetheless are still found to have a lasting impact on experienced returns which, in turn, affect the willingness of households to take financial risk. Households are found to be more sensitive during the GFC where the overall effect of a large decline in experienced returns (from the 90th to the 10th percentile) more than tripled in absolute terms compared to pre-GFC levels, reverting back to near pre-GFC levels by 2015, a period of approximately 7 years. This change holds uniformly for all households regardless of age suggesting that whilst the GFC affected the willingness of households to take financial risk, the change was the same for both older and younger households. The empirical results also provide evidence that high and low income earners behave differently in response to negative financial shocks, whereas the results are independent of other household characteristics including 
education, employment status and being a recipient of dividend income.

The occurrence of increased myopia stemming from the GFC is consistent with the existing results by Kandasamy et al. (2014), Cohn et al. (2015) and Guiso et al. (2018). The empirical finding that investor's willingness to take risk took approximately 7 years to recover from the effects of the GFC differs from the results of Hoffmann et al. (2013) who find a much shorter recovery time period of approximately one year, while Weber et al. (2013) find no change in risk attitudes. ${ }^{3}$ Part of the reason for this difference in results is that Weber et al. (2013) used a very short time period of data which was recorded near the start of the GFC at a time when the financial crisis was beginning to manifest itself (Guiso et al. (2018)). In contrast, the current empirical study is based on a long panel of data ranging from 2001 to early 2008 (pre-GFC period) and from the second part of 2008 to 2015 (GFC and post-GFC periods), thereby allowing for any changes in risk attitudes arising from financial shocks to be fully captured over time.

An important implication of our empirical results is that it is possible to reconcile differences in risk taking behaviour reported in the literature using a similar modelling framework, but for different countries. This arises because of the generality of the proposed model specification, as well as the use of a relatively long sample period in the empirical analysis which encompasses the pre-GFC as well as the GFC and post-GFC periods.

The rest of the paper proceeds as follows. The data are discussed in Section 2. An empirical model is specified in Section 3, which is applied in Section 4. Implications of the empirical results for the life cycle and the distribution of income, as well as other household characteristics are discussed in Section 5. Robustness of the results to the inclusion of a volatility measure is investigated in Section 6, with conclusions and policy implications given in Section 7.

\footnotetext{
${ }^{3}$ Malmendier and Nagel (2011) use a counterfactual experiment based on pre-GFC parameter estimates with a constant weighting scheme and find the effects of the GFC could last for up to 30 years. An important difference in the present paper compared to the model specified by Malmendier and Nagel is that the weighting scheme is allowed to vary in response to the large shocks of the GFC, adding an important element to the impact of financial shocks.
} 


\section{Data}

The data on the willingness of households to take financial risk is taken from the Household Income and Labour Dynamics in Australia (HILDA) survey, a nationally representative household panel study collected annually since 2001; see Summerfield et al. (2015) for more details of the HILDA survey. This survey has been used to study the impact of the GFC on Australian households by Miller (2014) and Frijters et al. (2015), and more recently by Cardak et al. (2019) who focus on stock holding decisions. Households were surveyed on financial risk in all waves from 2001 to 2015, except for 2005, 2007 and 2009. Following Malmendier and Nagel (2011), the sample is restricted to observations where the household head is aged between 25 and 74, with an annual household income of at least $\$ 1000$ per annum expressed in real 2010 Australian dollars. ${ }^{4}$ This yields a sample of 51950 observations.

The survey provides an ordinal measure of household willingness to take financial risk based on the following question: ${ }^{5}$

Which of the following statements comes closest to describing the amount of financial risk that you are willing to take with your spare cash? That is, cash used for savings or investment.

1. I am not willing to take any financial risks

\section{I take average financial risks expecting average returns}

3. I take above-average financial risks expecting to earn above-average returns

\section{I take substantial financial risks expecting to earn substantial returns}

These responses are respectively referred to as None $(y=1)$, Average $(y=2)$, Above Average $(y=3)$ and Substantial $(y=4)$ in the discussion below to denote the level of risk households are willing to take. This question is comparable to that asked of households in the U.S. with the Survey of Consumer Finances (SCF) and in Europe with the Eurosystem Household Finance and Consumption Survey (HFCS) and respectively

\footnotetext{
${ }^{4}$ Relaxing these sample restrictions does not qualitatively change the results.

${ }^{5}$ This order of categories is the reverse of that presented in the HILDA survey, allowing higher values to represent greater willingness to take risk. The category where households respond that they never have any spare cash is omitted as it contains no information regarding willingness to take risk.
} 
used by Malmendier and Nagel (2011) and Ampudia and Ehrmann (2017). As in Malmendier and Nagel (2011), this measure of risk tolerance is referred to as elicited risk tolerance. ${ }^{6}$ Summary statistics of the responses to the HILDA question are presented in Table A.1 in the Online Appendix.

The GFC began in 2008. As households were interviewed throughout 2008, two groups of households are identified in the 2008 wave. The first group were interviewed prior to some of the key GFC events occurring in second half of 2008, while the second group were interviewed after those events. The threshold date chosen is September 26, determined by a combination of institutional events as well as some preliminary sensitivity analysis. The total number of households in the 2008 wave is 3601, with 2198 households being interviewed prior to the threshold date and the remaining 1403 interviewed after the threshold date. Therefore, the benchmark period corresponding to the pre-GFC period consists of the 2001-04 and 2006 waves, as well as those households interviewed prior to September 26 in 2008. The households interviewed on or after September 26 in 2008 correspond to observations at the start of the GFC, while the 2010-15 waves provide post GFC observations which include other financial shocks such as the European debt crisis which began in late 2009.

Table 1 gives the transition matrix of households willingness to take risk from 2006 to the 2008 crisis period and from 2006 to 2012, expressed as a percentage. Cells along the main diagonal represent those households who do not change their elicited risk tolerance between the two periods, whereas cells below (above) the main diagonal correspond to households who reduce (increase) their willingness to take risk during the GFC.

The transition matrix between 2006 and 2008 shows that one third of households changed their risk taking behaviour at the start of the financial crisis in 2008 (100 24.97 - 34.12 - 6.59 - $0.98=33.34)$. Of these households, approximately half lowered their elicited risk tolerance $(17 \%)$ with the other half actually increasing it (16\%). A similar pattern occurs for the 2006 - 2012 transition matrix where the proportion of households who change their elicited risk tolerance is $35 \%$, whereas the proportion of households lowering their willingness to take risk is now $20.7 \%$ while those increasing

\footnotetext{
${ }^{6}$ Similar measures of risk tolerance have been shown to strongly predict risk taking by households (Dohmen et al. (2011)). However, this risk taking measure is different to other measures based on data where respondents answer questions about explicit gambles (Barsky et al. (1997) and Guiso and Paiella (2008)).
} 
their willingness to take risk comprises $14.5 \%$.

Table 1: Transition matrices of household willingness to take risk between precrisis and crisis periods for selected years.

\begin{tabular}{|c|c|c|c|c|c|c|}
\hline \multirow{2}{*}{$\square$} & & \multicolumn{4}{|c|}{2008 (GFC) } & \multirow[b]{2}{*}{ Total } \\
\hline & & None & Average & Above & Substantial & \\
\hline & None & 24.97 & 9.14 & 0.49 & 0.29 & 34.91 \\
\hline & Average & 9.73 & 34.12 & 4.62 & 0.39 & 48.87 \\
\hline & Above & 0.79 & 5.31 & 6.59 & 1.18 & 13.86 \\
\hline & Substantial & 0.39 & 0.69 & 0.29 & 0.98 & 2.36 \\
\hline & Total & 35.89 & 49.26 & 12.00 & 2.85 & 100.00 \\
\hline & & \multicolumn{4}{|c|}{2012} & \\
\hline & & None & Average & Above & Substantial & Total \\
\hline & None & 25.69 & 8.22 & 0.51 & 0.17 & 34.60 \\
\hline & Average & 11.63 & 34.26 & 4.22 & 0.51 & 50.62 \\
\hline & Above & 1.19 & 5.96 & 4.09 & 0.89 & 12.14 \\
\hline & Substantial & 0.55 & 0.47 & 0.85 & 0.77 & 2.64 \\
\hline & Total & 39.07 & 48.91 & 9.67 & 2.34 & 100.00 \\
\hline
\end{tabular}

Figure 1 provides a decomposition of the household risk tolerance data in terms of household age beginning with the youngest group of 25-29, to the oldest group of 70-74. The decomposition is computed by averaging the responses of all households in each of the 4 risk tolerance categories from 2001 to 2015 for each age group. Apart from the small increase in this measure between the 25-29 and 30-34 groups, willingness to take risk declines with age, with the size of the decline progressively increasing with age, resulting in the oldest households having the lowest tolerance for risk. Similar results are presented by Sahm (2012) for the U.S. and by Dohmen et al. (2017) for Germany and the Netherlands.

\section{A Model of Elicited Risk Tolerance}

An empirical model is now specified to capture the effects of financial shocks on the elicited risk tolerance of households. An important feature of the modelling framework is how past stock returns are reevaluated during periods of financial stress. Denoting 


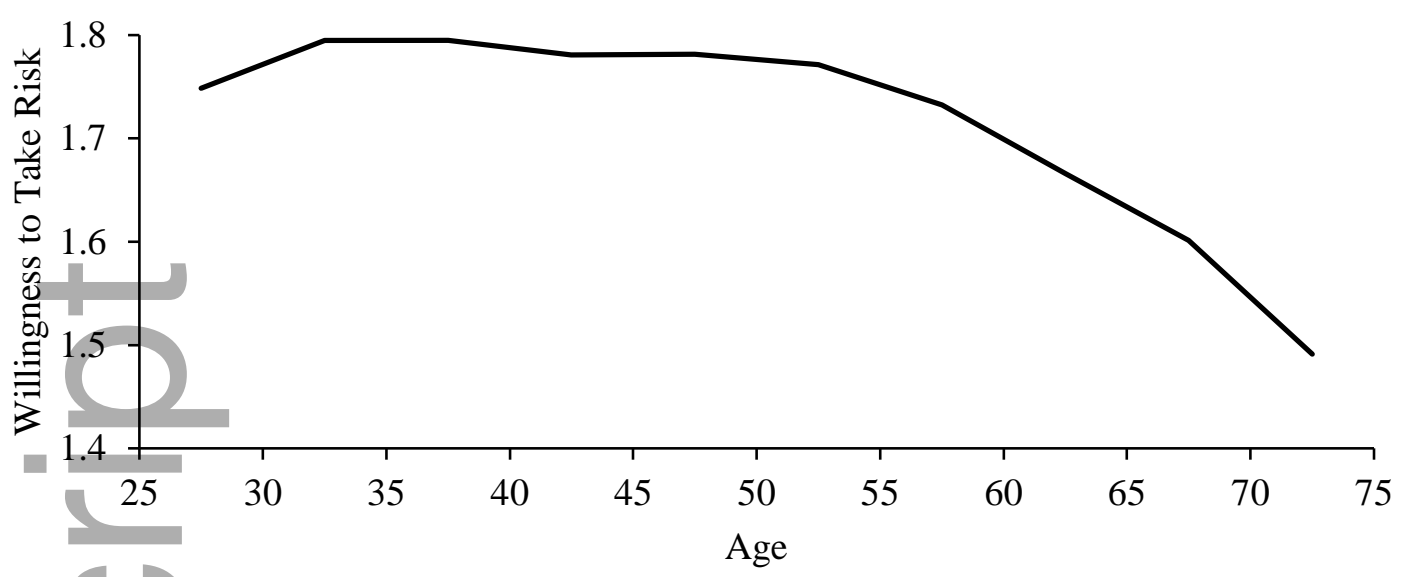

Figure 1: Average willingness to take financial risk by age groups for full sample period (2001-2015).

the (unobserved) measure of risk tolerance of household $i$ at time $t$ as $y_{i t}^{*}$, the model is specified as

$$
y_{i t}^{*}=\alpha+\beta \sum_{k=1}^{\text {age }_{i t}-1} w_{i t}\left(k, \lambda_{t}\right) r_{t-k}+\gamma^{\prime} x_{i t}+\varepsilon_{i t} .
$$

Equation (1) expresses $y_{i t}^{*}$ as a weighted average of past real stock returns $r_{t-k}$, over the life of the household at $a g e_{i t}$, with the weights given by $w_{i t}$, a set of control variables $x_{i t}$, and a disturbance term $\varepsilon_{i t}$ which is assumed to have zero mean and constant variance. Malmendier and Nagel (2011) refer to the weighted returns as "experienced" returns.

The weighting scheme in (1) is specified as

$$
w_{i t}\left(k, \lambda_{t}\right)=\frac{\left(a g e_{i t}-k\right)^{\lambda_{t}}}{\sum_{s=1}^{a g e_{i t}-1}\left(a g e_{i t}-s\right)^{\lambda_{t}}},
$$

with $\lambda_{t}$ representing a time-varying parameter controlling how past returns affect $y_{i t}^{*}$. This choice of specification represents a flexible weighting scheme that can generate a broad range of patterns with a parsimonious number of parameters. In the special case where $\lambda_{t}=0$, all past real stock returns are equally weighted over the life of the household with weights of $1 /\left(a g e_{i t}-1\right)$. For values of $\lambda_{t}>0$, more recent returns are given relatively greater weight than more distant returns. If $\lambda_{t}=1$, the weighting function decreases linearly over time, whereas for $\lambda_{t}>1$, the weighting function assigns even more weight to recent returns and less to past returns than is the case for a linear weighting scheme. In the case of $\lambda_{t}<0$, it is past returns that have a relatively greater impact on experienced returns than do more recent returns. 
The weighting parameter $\lambda_{t}$ in (2) is allowed to be time-varying in order to identify potential changes in the risk taking behaviour of households as a result of the GFC in 2008, as well as during the post-GFC period, 2009 to 2015. This is achieved by specifying the following equation

$$
\lambda_{t}=\phi_{\text {pre }}+\phi_{0} d_{2008, t}+\phi_{1} d_{2009, t}+\phi_{2} d_{2010, t}+\phi_{3} d_{2011, t}+\phi_{4} d_{2012, t}+\phi_{5} d_{2013, t}+\phi_{6} d_{2014, t}+\phi_{7} d_{2015, t}
$$

where $d_{j, t}$ is a time indicator variable defined as

$$
d_{j, t}= \begin{cases}1: & t=j \\ 0: & \text { otherwise. }\end{cases}
$$

This specification assumes that households adopt the same weighting scheme at each point in time prior to the GFC given by $\lambda_{t}=\phi_{\text {pre }}$, which consists of households interviewed in wayes from 2001 to those interviewed in the 2008 wave prior to September 26. The restriction that the weighting parameter is fixed during the pre-GFC period is motivated by the specification adopted by Malmendier and Nagel (2011) who also specified a fixed weighting parameter. As this model was estimated using only preGFC data, the pre-GFC component of the model of risk tolerance specified in this paper effectively represents the Malmendier and Nagel model, thereby serving as a benchmark for comparison with their results. The pre-GFC component of the model also provides an appropriate baseline from which to identify potential changes in the weighting parameter during the GFC and post-GFC periods. The wave indicator variable $d_{2008, t}$ in (3) allows for the experienced returns weighting scheme to change at the time of the GFC in 2008 by $\phi_{0}$ from its pre-GFC value of $\phi_{\text {pre }}$, in which case the 2008 precrisis and 2008 crisis households are weighted according to $\lambda_{2008}$ precrisis $=\phi_{\text {pre }}$ and $\lambda_{2008 \text { crisis }}=\phi_{\text {pre }}+\phi_{0}$ respectively. The remaining parameters $\phi_{1}, \phi_{2}, \cdots, \phi_{7}$ in (3), allow for the effects of the GFC shock to change over time during the post-GFC period. ${ }^{7}$

To identify the $\phi_{i}$ parameters in (3) there needs to be sufficient variation in experienced returns at each point in time during the GFC and post-GFC years. In the extreme case where $\lambda_{t} \rightarrow \infty$, more and more of the weight is loaded on the most recent stock return and less weight on all other past returns. In this extreme case the effective lag length is 1 year, with all households having the same experienced return equal to

\footnotetext{
${ }^{7}$ In the empirical analysis in Section 4, as data are not available for 2009, the estimated model presented excludes the variable $d_{2009, t}$ in (3). However, an estimate of the parameter $\phi_{1}$ is obtained implicitly via the polynomial specification defined in equation (4) below.
}

This article is protected by copyright. AlBrights reserved 
the most recent stock return. In this situation there would be sufficient variation in the experienced returns at each point in time during the GFC period to identify the $\phi_{i}$ parameters assuming there is sufficient variation in real stock returns. For the other extreme case as $\lambda_{t} \rightarrow 0$, the effective lag length is the age of the household, with all weights equaling $1 /\left(a g e_{i t}-1\right)$ when $\lambda_{t}=0$. In this situation there is unlikely to be sufficient variation in a household's experienced returns at each point in time during the GFC as these returns will only change marginally from one year to the next by the weighted addition of the most recent stock return with weight $1 /\left(\right.$ age $\left._{i t}-1\right)$. For a 50 year old household this weight is approximately 0.02 , which becomes even smaller for older households.

This identification problem is akin to estimating distributed lag models with many lagged variables where the sample variation between lags is insufficient to generate precise estimates of the pertinent parameters. ${ }^{8}$ To address the issue and improve the precision of the estimates of $\phi_{i}$, the effective number of parameters chosen to capture time variation in the weighting parameter is reduced by specifying the following $M^{\text {th }}$ order polynomial

$$
\phi_{l}=\sum_{j=0}^{M} \delta_{j} l^{j},
$$

where $\delta_{j}$ are $M+1$ unknown parameters. ${ }^{9}$ Identification of the $\phi_{l}$ parameters is achieved by reducing the number of unknown parameters to $M+1$ where $\operatorname{dim}(M+1)<7$, and using the full sample to identify the $\delta_{0}, \delta_{1}, \cdots, \delta_{M}$ parameters, which, in turn, are used to recover the $\phi_{l}$ parameters in (4). ${ }^{10}$ The improvement in precision from (4) arises from reducing the number of unknown parameters that need to be estimated and using all information at each point in time to estimate this set of unknown parameters. In turn, the $\phi_{i}$ parameters are identified by interpolation using the polynomial specification.

In the case of a second order polynomial, $M=2$ in (4), the resulting $\phi_{l}$ parameters are identified from the three unknown parameters, $\delta_{0}, \delta_{1}$ and $\delta_{2}$, where the relationship

\footnotetext{
${ }^{8}$ Even in the case of a constant weighting parameter there is still an additional identification issue arising from the relationship between age, wave indicators and birth cohort. As age and wave indicators are included in the set of household characteristic variables in $x_{i t}$ in equation (1), experienced returns are interpreted as representing a nonlinear instrument for birth cohort (Heckman and Robb (1985)).

${ }^{9}$ Equation (4) was originally used by Almon (1965) to specify a flexible and parsimonious distributed lag model. This strategy has recently been adopted by Andreou et al. (2010) to specify and estimate mixed frequency regression models.

${ }^{10}$ In the empirical analysis of the model in Section 4 the $\delta_{i}$ parameters are estimated with the choice of $M$ in (4) determined by testing the significance of the Almon parameters.
} 
between the two sets of parameters is

$$
\begin{aligned}
& \phi_{0}=\delta_{0} \\
& \phi_{1}=\delta_{0}+\delta_{1}+\delta_{2} \\
& \phi_{2}=\delta_{0}+2 \delta_{1}+4 \delta_{2} \\
& \phi_{3}=\delta_{0}+3 \delta_{1}+9 \delta_{2} \\
& \phi_{4}=\delta_{0}+4 \delta_{1}+16 \delta_{2} \\
& \phi_{5}=\delta_{0}+5 \delta_{1}+25 \delta_{2} \\
& \phi_{6}=\delta_{0}+6 \delta_{1}+36 \delta_{2} \\
& \phi_{7}=\delta_{0}+7 \delta_{1}+49 \delta_{2} .
\end{aligned}
$$

This polynomial specification allows for a variety of patterns in the weighting scheme over time. Three examples are presented in Figure 2 with the choice of the parameters based on estimates obtained in Section 4.1. The precrisis weighting parameter is $\lambda=$ $\phi_{\text {pre }}=2$. For all three cases there is a jump in the weight, $\lambda_{t}$, after the crisis. In the case of the quadratic specification with $\delta_{0}, \delta_{1}, \delta_{2} \neq 0$ (continuous line), there is a further increase in the weights over the next two periods after the initial jump, with the weights declining thereafter. For the linear specification with $\delta_{2}=0$ (short dashed line), the weights decline linearly immediately after the initial shock. Imposing the restrictions $\delta_{1}=\delta_{2}=0$ (long dashed line), the weights are represented by a step function with a positive jump in the weight at the time of the crisis which remains at the same level after the shock. In the most restricted version of this model, $\delta_{0}=\delta_{1}=\delta_{2}=0$, which from (3) results in a fixed weighting parameter equal to $\phi_{\text {pre }}$ both before, during and after the crisis.

Figure 3 highlights the effects of a change in $\lambda_{t}$, due to a financial market shock, on the weighting function in equation (2) for two households: one with a 50 year old household head (Figure 3(a)), and the other with a 25 year old household head (Figure $3(\mathrm{~b}))$. The change in $\lambda_{t}$ is from the base period of $\lambda($ base $)=2$, to $\lambda($ shock $)=10 .{ }^{11}$ The effect of the shock is to make households relatively more myopic, with households placing a higher weight on more recent asset market returns and a lower weight on past returns. For the 50 year old household head, when $\lambda($ base $)=2$, the weights eventually

\footnotetext{
${ }^{11}$ The choice of parameters in Figures 3 and 4 are based on the empirical results presented in Section 4.1 , with the $\lambda($ shock $)=10$ value representing the average estimate of $\lambda_{t}$ over the post-GFC period.
} 


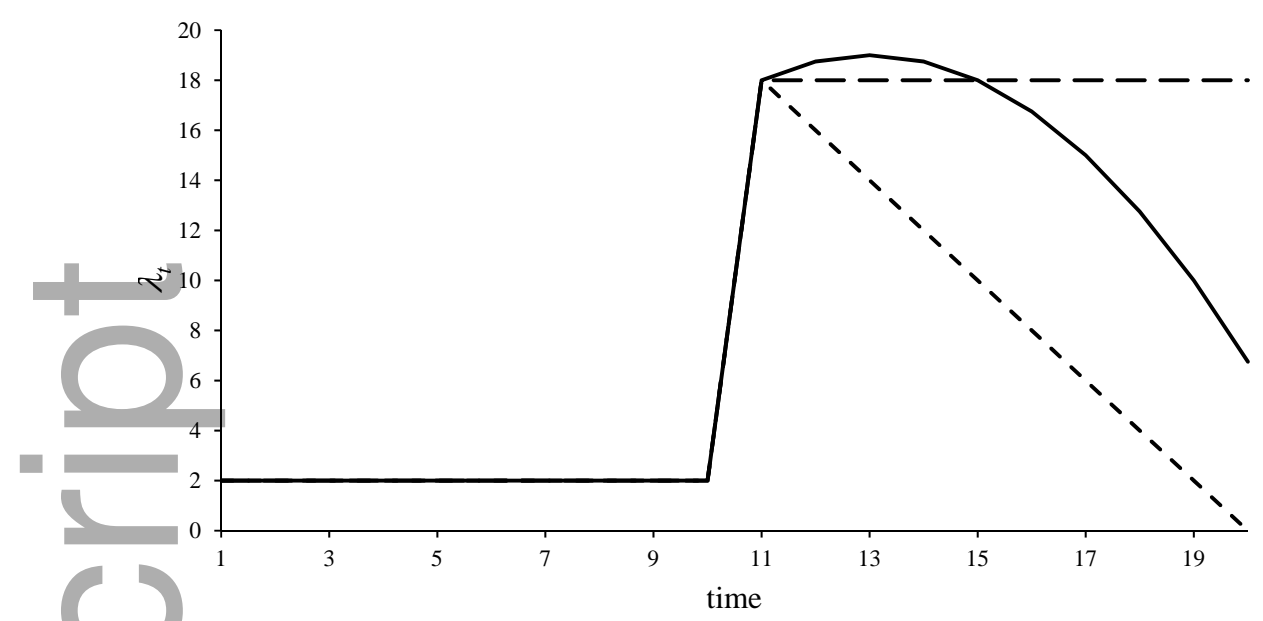

Figure 2: Values of the experienced returns weighting parameter $\lambda_{t}$, based on equations (3) and (5) with $\phi_{\text {pre }}=2$ and (i) Quadratic: $\delta_{0}=16, \delta_{1}=1, \delta_{2}=-0.25$ (continuous); (ii) Linear: $\delta_{0}=16, \delta_{1}=-2, \delta_{2}=0$ (short dashed); (iii) Step: $\delta_{0}=16, \delta_{1}=0, \delta_{2}=0$ (long dashed).

become zero for the time of birth i.e. 50 years into the past. This is not the case for the weights post shock with returns beyond 20 years receiving a zero weight. The effects of the same changes in the weighting parameter for the younger household head of 25 years is to place even greater weight on recent returns than 50 year old households. Prior to the shock younger households assign non-zero weights to all returns over their lifetime, whereas after the shock it is the most recent 10 years of returns that are most important.

The effect of a shock on the distribution of experienced returns is demonstrated in Figure 4 using households from the 2015 wave of the survey. In computing experienced returns for each household, data on real stock returns for Australia begin in 1920 and end in 2015, where years are in terms of financial years (see Online Appendix A.2 for a description of the data on real stock returns). Two distributions are presented based on the following scenarios: the first is the base distribution with $\lambda$ (base) $=2$ (continuous line) and the second is the post-shock distribution with $\lambda($ shock $)=10$ (dashed line). The effect of increasing $\lambda_{t}$ is to make the experienced returns distribution more compact as greater weight is placed on a smaller range of past real stock returns. There is also a downward shift in the distribution after the shock which is a reflection that recent past stock returns prior to 2015, namely the negative stock returns experienced during the GFC and post-GFC periods, are on average lower than real stock returns further 
(a) Household head age $=50$

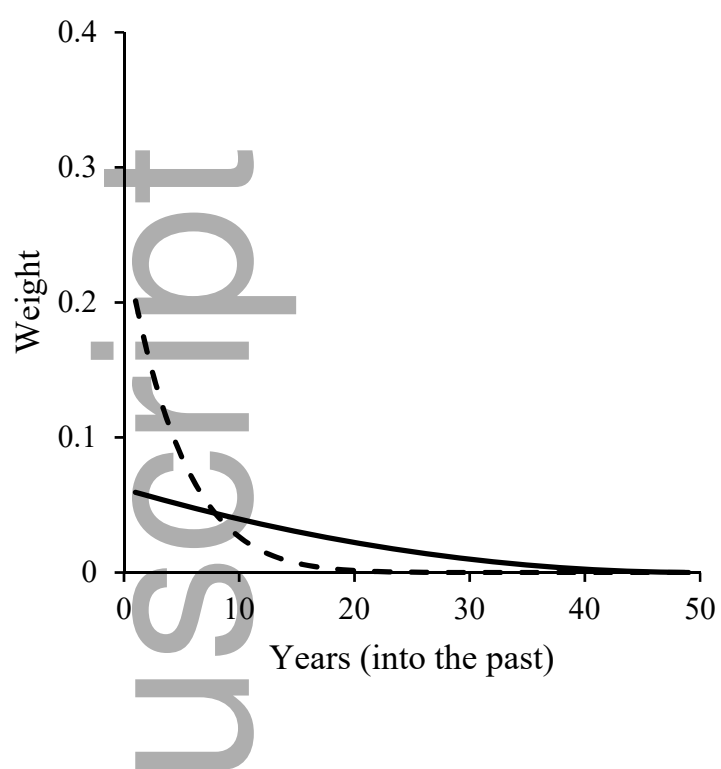

(b) Household head age $=25$

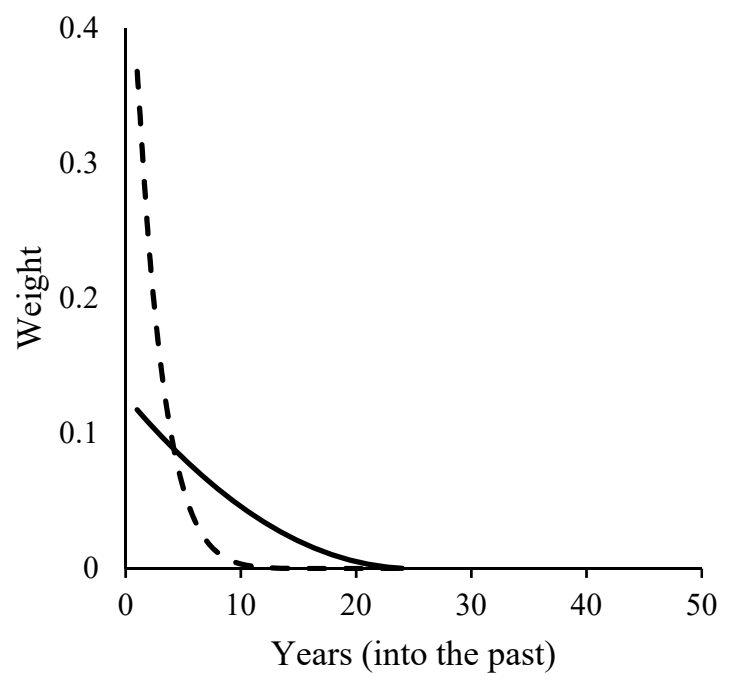

Figure 3: Effect of a shock on the weighting function in equation (2) for 50 year old (panel (a)) and 25 year old (panel (b)) household heads. The base period weighting parameter is $\lambda($ base $)=2$ (continuous line), and the shock period weighting parameter is $\lambda($ shock $)=10$ (dashed line).

into the past.

To complete the specification of the model the relationship between the unobserved risk tolerance measure $y_{i t}^{*}$ in (1), and the elicited measure of risk tolerance $y_{i t}$, is given by

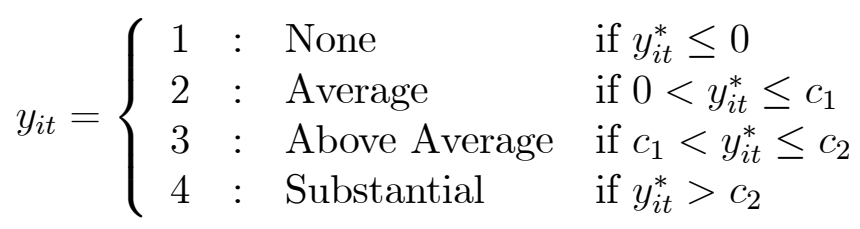

where $0<c_{1}<c_{2}$ represent the "cut-off" parameters. Assuming the disturbance term $\varepsilon_{t}$ in equation (1) is normally distributed the model is an ordered probit containing 4 categories.

\section{Empirical Analysis}

The model presented in equations (1) to (6) in Section 3 is now estimated by maximum likelihood methods using the data on elicited risk tolerance discussed in Section 2. The sample period consists of 12 waves from 2001 to 2015, with the pre-GFC period given by 2001 to 2008 precrisis waves, the GFC period given by the 2008 crisis wave, and 


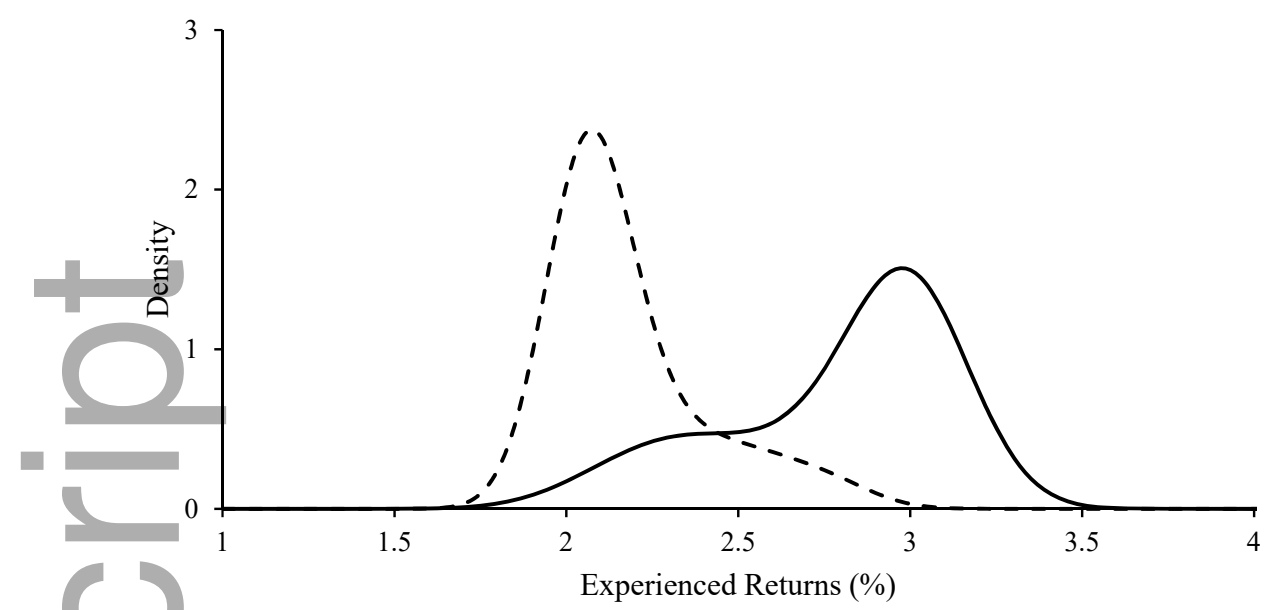

Figure 4: Empirical experienced returns (\% p.a.) distribution for alternative values of the weighting parameter: $\lambda$ (base) $=2$ (continuous line) and $\lambda$ (shock) $=10$ (dashed line). Based on households in the 2015 wave.

the post-GFC period given by the 2010 to 2015 waves. The control variables $x_{i t}$ in (1) consist of income, education, immigrant, retirement and marital status, gender, number of dependent children, age, and a set of wave indicators to allow for period effects (see Table A.1 in the Online Appendix for summary statistics of the control variables). ${ }^{1}$

The parameters of the model $\theta=\left\{\alpha, \beta, \phi_{\text {pre }}, \delta_{0}, \delta_{1}, c_{1}, c_{2}, \gamma\right\}$ are estimated using maximum likelihood. An iterative gradient algorithm is used as a result of the nonlinearities arising from the ordered probit specification, as well as from the nonlinear specification in (1) linking experienced returns as a nonlinear function of the parameters used to construct the time-varying weighting parameter $\lambda_{t}$. All calculations are performed using GAUSS, Version 14, with the iterations based on the BFGS algorithm with the derivatives computed numerically.

\subsection{Parameter Estimates}

The maximum likelihood estimates of the key parameters of the model are presented in Table 2 with QMLE standard errors given in parentheses. The complete set of parameter estimates for all models are given in Table A.2 in the Online Appendix. ${ }^{13}$ Three

\footnotetext{
${ }^{12}$ The wave indicator variables control for potential reverse causality from the dependent variable to stock returns as well as other unobserved time-varying "aggregate factors" which may affect stock returns (Malmendier and Nagel, (2011, p.390)).

${ }^{13} \mathrm{~A}$ variation of the estimated models presented in Table 2 applies the weight $\lambda_{2008}=\phi_{\text {pre }}+\phi_{0}$ to all households interviewed in 2008 thereby treating them all as crisis period observations. These
} 
sets of parameter estimates are presented in Table 2, depending upon the constraints imposed on the parameters $\delta_{0}$ and $\delta_{1}$ in (4). ${ }^{14}$ The first is the model based on a Linear weighting specification $\left(\delta_{0}, \delta_{1} \neq 0\right)$ which allows the weights to change each year over the GFC period. The second is a more restrictive model with the weights represented by a Step function at the time of the GFC $\left(\delta_{0} \neq 0, \delta_{1}=0\right)$, with the shock having a permanent effect on the experienced returns weighting scheme. The third model presented is the most restrictive specification in which the weights for the pre-GFC and GFC periods are constrained to be equal to the weighting parameter $\phi_{\text {pre }}$ by setting the parameters $\delta_{0}=\delta_{1}=0$. This model is referred to as the Fixed parameter model.

A likelihood ratio test between the Linear and Step model specifications produces a test statistic of 4.779 with a $p$-value of 0.029 , resulting in the Step model specification being rejected at the $5 \%$ level. A likelihood ratio test between the Linear and the most restrictive model as given by the Fixed model specification, yields a value of 8.000 with a $p$-value of 0.018 , implying the most restricted version of the model is also rejected at the $5 \%$ level. These results not only provide strong support the weighting parameter changed at the time of the GFC in 2008, but it also changed over time during the post-GFC period.

Table 2 shows that the estimate of the weighting parameter during the precrisis period $\phi_{\text {pre }}$, based on the Linear model specification is 1.951. As this estimate is statistically different from zero this suggests that prior to the GFC more recent stock returns received a relatively higher weight, although distant returns nonetheless still had some influence. Inspection of the parameter estimates of $\delta_{0}$ and $\delta_{1}$ for the Linear model specification in Table 2, provides evidence of time-variation in the experienced returns weighting scheme during the GFC and post-GFC periods, as both parameter estimates are statistically significant at the $1 \%$ level. This result is also consistent with the likelihood ratio model specification tests. Moreover, the immediate effect of the GFC on elicited risk tolerance is highlighted by the non-zero estimate of $\delta_{0}$, with the weighting parameter $\lambda_{t}$, increasing from 1.951 in the pre-GFC period to $1.951+15.586=17.537$ results are presented in Table A.3 in the Online Appendix.

${ }^{14}$ In the initial specification of the model a quadratic weighting scheme was adopted by setting $M=2$ in (4) and allowing $\delta_{2} \neq 0$. This specification however, produced insignificant parameter estimates and a formal test of the restriction $\delta_{2}=0$ using a likelihood ratio test could not be rejected. The estimates of this specification therefore were excluded from Table 2. For completeness the results of the model based on a quadratic polynomial are presented in Table A.2 in the Online Appendix. 


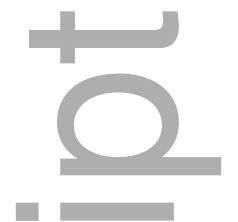

Table 2: Maximum likelihood parameter estimates of the elicited risk tolerance model, with QMLE standard errors in parentheses. Based on a sample size of $N=51950$. Columns (1), (2) and (3) contain the Linear $\left(\delta_{0}, \delta_{1} \neq 0\right)$, Step $\left(\delta_{0} \neq 0, \delta_{1}=0\right)$ and Fixed $\left(\delta_{0}=\delta_{1}=0\right)$ models respectively, where $* * *$ and $* *$ denote significance at the $1 \%$ and $5 \%$ levels respectively.

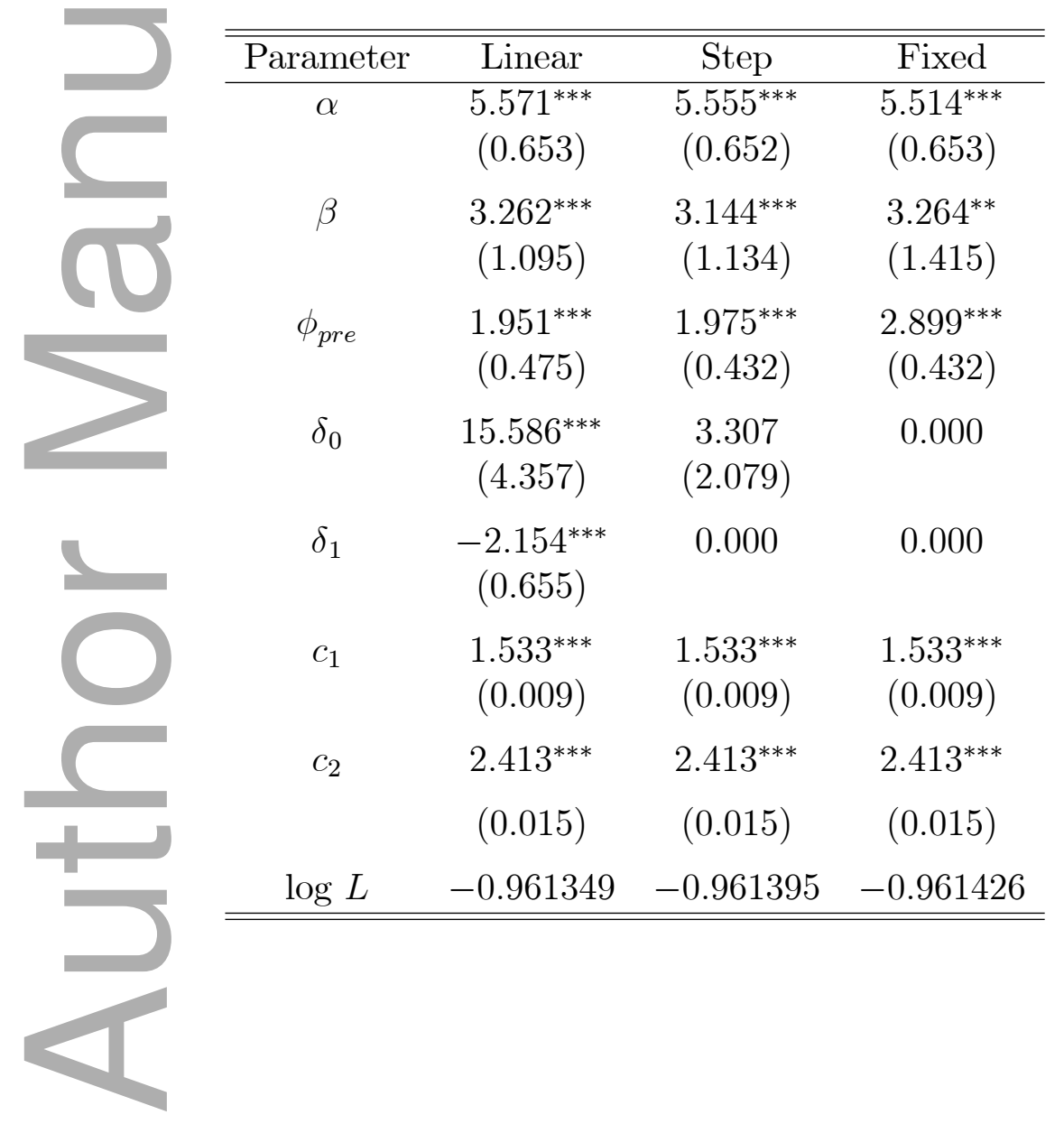




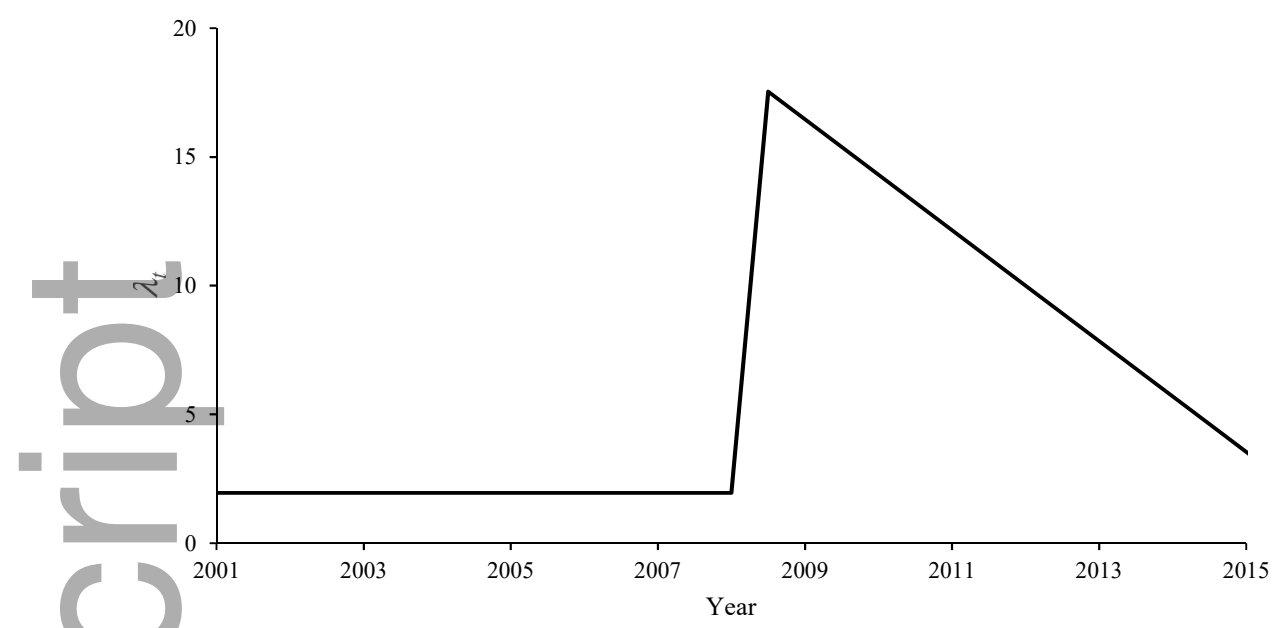

Figure 5: Estimated values of time varying weighting parameter $\lambda_{t}$ based on Linear model estimates from Table 2 .

at the start of the GFC in the latter part of 2008. This increase implies that households at the time of the GFC placed greater weight on the most recent real stock returns when evaluating experienced returns, leading to more myopic responses to questions on willingness to take financial risk. It is estimated that a 25 year old household head increases the weight placed on the most recent stock return from $12 \%$ before the GFC to $54 \%$ after, while for a 50 year old household head the weight increases from $7 \%$ to $32 \%$. The larger absolute impact on younger households is due to the fact that they have a shorter horizon of past experiences from which to draw on and as a consequence their most recent experiences receive a greater weight than for older households. However, both increases are approximately 4.5 times implying in relative terms the impact of the GFC, through experienced returns, on the elicited risk tolerance of the young and old are similar, a result considered further in the life cycle analysis in Section 5.1.

An important feature of the empirical results in Table 2 is that the parameter $\delta_{1}$ in (4), is negative and statistically significant, implying that the weighting parameter $\lambda_{t}$ in (3), declines over time during the GFC period. The weighting parameter estimates are presented in Figure 5 and show that they approach the pre-GFC estimate of 1.951 by 2015 , suggesting that the effects of the GFC on household willingness to take risk largely dissipated after nearly 7 years.

The estimate of the weighting parameter for the pre-GFC period $\phi_{\text {pre }}$, is very similar in magnitude to the estimate of 1.83 reported by Malmendier and Nagel (2011) for the 
U.S. based on pre-GFC data. ${ }^{15}$ In particular, the estimate for the U.S. is within 2 standard deviations of the estimate of 1.95 reported here for Australian households during the precrisis period. ${ }^{16}$ These estimates are nonetheless lower than the estimate of 4.64 reported by Ampudia and Ehrmann (2017, Table 3) for European households. However, the sample period used by Ampudia and Ehrmann is 2008 to 2010, which coincides with the GFC and the period immediately after the GFC. This suggests that the more relevant comparison is with the estimates reported for Australia during the GFC and post-GFC periods presented in Figure 5. These estimates range from 17.5 for the GFC period, decreasing linearly over the post-GFC period and falling to 2.4 by 2015 , with an average weight of just under 10. Whilst this estimate is over twice the size of the weighting parameter estimate reported for Europe, it nonetheless provides further support for the result that the GFC led households to become more myopic. This result also offers a way to reconcile differences between the U.S. and European results: the fundamental difference between these two empirical studies is that the U.S. study is based on pre-GFC data whereas the European study is based on GFC data, causing the European estimate to be inflated by the impact of the GFC upon the willingness to take risk.

The estimate of the parameter $\beta$ reported in Table 2 for the Linear model specification is positive and highly significant with a value of 3.26 , providing strong evidence that experienced returns represent an important determinant of households' risk tolerance. This estimate is marginally lower than the estimate of 4.53 reported by Malmendier and Nagel (2011), but nonetheless is well within 2 standard deviations of the U.S. estimate based on the standard error of 1.095 reported for the estimate of $\beta$ in Table 2.

\footnotetext{
${ }^{15}$ The estimate of the weighting parameter for the U.S. is taken from Malmendier and Nagel (2011), Table II, column (i) and based on their model that excludes liquid assets (defined as stock holdings plus bonds plus cash and short-term instruments) as a control variable. This is the appropriate comparison as the empirical results presented in this paper do not include data on household wealth as it is not collected in eight of the 12 waves used.

${ }^{16}$ In comparison, the estimate of $\phi_{\text {pre }}$ for the Fixed model specification where the weighting parameter is assumed to be same over the full sample period, is 2.899 from Table 2 which represents an over-estimate of the pre-GFC experienced returns weighting parameter, but an under-estimate of the corresponding figure for the post-GFC period.
} 


\subsection{Experienced Returns Distributions}

Figure 6 shows the evolution of the estimated experienced returns distributions for selected periods: the pre-GFC period (2001 to September 25, 2008), the 2008 GFC period from September 26 to the end of the year, and the post-GFC periods of 2010 and 2012. The pre-GFC period experienced returns distribution is positive with a mean of around $4 \%$ per annum. For the post-GFC experienced returns distributions there is a leftward shift in 2010 with an average of $-1.8 \%$, and a further negative shift in 2012 with an average of $-6.5 \%$.

Interestingly, the experienced returns distribution during the 2008 GFC period shifts upwards from the pre-GFC experienced returns distribution with a mean of around 5.4\%, as well as becoming more compact with a lower standard deviation. The reduction in the standard deviation arises as greater weight is placed on more recent real stock returns which has the effect of narrowing the potential range of past stock returns that household experienced returns are computed on. The positive shift in the distribution arises even though greater weight is placed on the large negative real stock return of $-16.7 \%$ in the 2008 financial year, this negative return is offset by the increased weights attached to the large positive real stock returns in financial years just prior: $25.8 \%$ (2007), $13 \%$ (2006), $17 \%$ (2005) and $12.6 \%$ (2004).

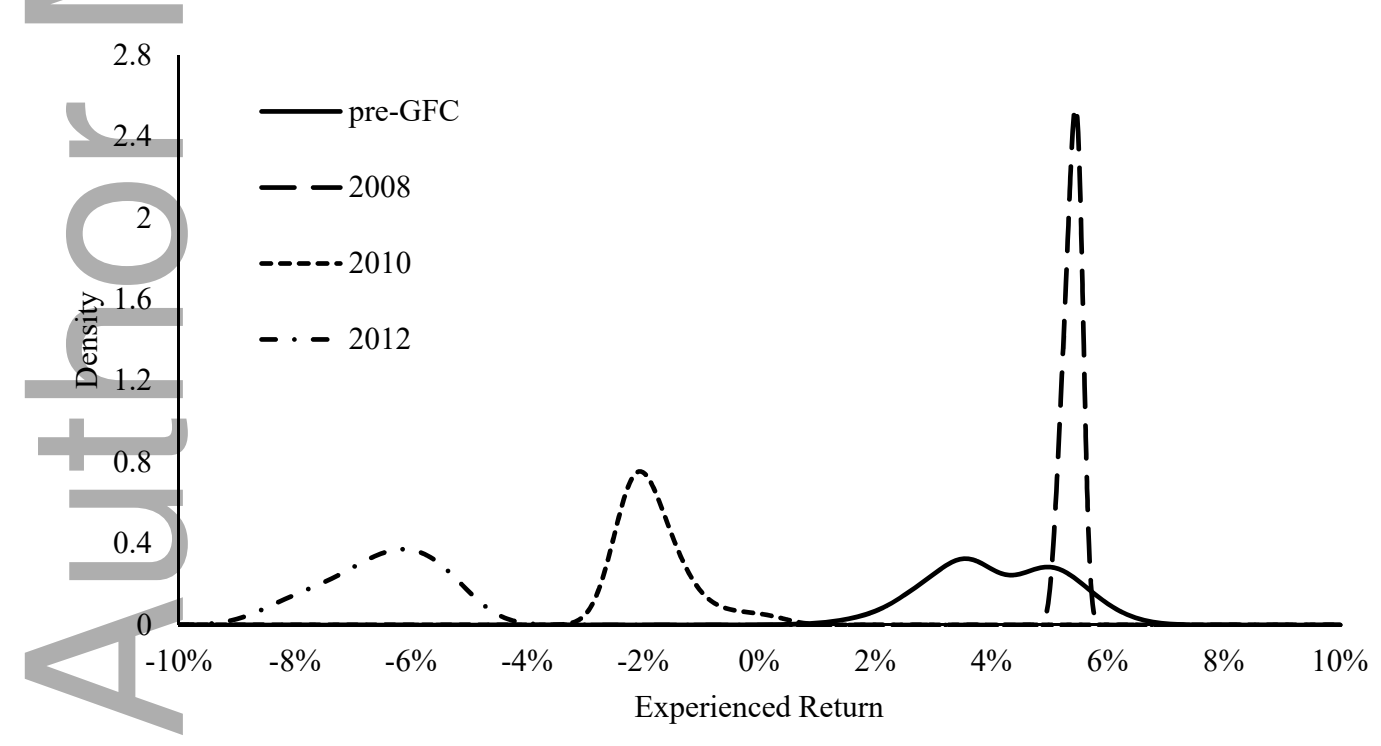

Figure 6: Estimated experienced returns distributions for the pre-GFC period 2001 to September 25 2008, and for selected years during the GFC (2008) and post-GFC periods $(2010,2012)$. Returns are expressed as a percentage per annum. 


\subsection{Effects of the GFC on Elicited Risk Tolerance}

The effects of the GFC on elicited risk tolerance are now investigated by comparing the sensitivity of household risk tolerance to a negative shock in experienced returns during the GFC and pre-GFC periods. The approach consists of estimating the probabilities of each of the four risk tolerance categories of the model for each household at the $90^{\text {th }}$ and $10^{t h}$ percentiles of the experienced return distribution, while holding all of the other variables fixed at their observed values, and averaging the difference between the two probabilities within each risk tolerance category over all households (Malmendier and Nagel (2011)). The changes in the probabilities from a decline from the $90^{\text {th }}$ to the $10^{\text {th }}$ percentile in the experienced returns distribution are evaluated using the parameter estimates of the Linear model reported in Table 2.

The results are reported in 3 for the 4 risk tolerance categories of $y_{i t}$ during the GFC and post-GFC years, 2008 to 2015, with standard errors based on the delta method given in parentheses. For comparison the changes in the probabilities from the negative shock in the experienced returns distribution are also reported for the pre-GFC years from 2001 to 2008 (pre September 26). The results provide very strong evidence of households reducing their risk tolerance during the GFC and post-GFC periods. The main movement is from the highest risk tolerance category "Substantial" to the lowest risk tolerance category "None". The initial impact of the negative shock during the GFC in 2008 causes a reduction of $-6.5 \%$ in the probability of being in the highest risk tolerance category, with the greatest impact occurring in 2012 where the change in probability is $-6.8 \%$. These reductions in probabilities in the highest risk tolerance category are reflected by increases in the probabilities in the "None" category of $3.8 \%$ in the 2008 GFC period and $4.2 \%$ in 2012 . There is also evidence that households reduce their risk tolerance, but nonetheless are still willing to take on some risk, with increases in the probabilities for the "Average" risk tolerance category of $2.1 \%$ in the 2008 GFC period and $2.0 \%$ in 2012 . In contrast, the changes in the probabilities for the "Above" risk tolerance category are positive but small in magnitude, suggesting that households when faced with a large negative financial shock significantly reduce their risk tolerance.

A comparison of the changes in probability reported in Table 3 between the preGFC and GFC years 2008 to 2012, reveals a large difference in risk tolerance from a 
negative shock in experienced returns. In 2006 for example, the change in probability from a negative shock is just $-2.3 \%$ for the highest risk tolerance category and $1.4 \%$ for the lowest, which are approximately one third of the corresponding GFC estimates reported for 2008 to $2012 .{ }^{17}$ Interestingly, a comparison of the probabilities between the pre-GFC and the post-GFC years, 2013 to 2015, suggests the effects of the GFC on household risk tolerance had dissipated with changes in risk tolerance behaviour reverting back to pre-GFC levels.

As experienced returns during the GFC adjust because of changes in both the weighting parameter and stock returns, Table 3 also provides the changes in probability from the decline in experienced returns during the GFC and post-GFC periods based on the pre-GFC estimated weight of 1.951 under the header "Pre-GFC Weights" to identify the relative strengths of these two channels. A comparison of the two sets of results shows that the probability differences based on pre-GFC weights are much smaller, suggesting that the changes in the estimated probabilities during the GFC period are largely the result of the change in the weighting scheme and not from a decline in stock returns.

\section{Risk Tolerance Decompositions}

The probability differences from changes in experienced returns on elicited risk tolerance presented in Table 3 are now decomposed in terms of household characteristics. Both life cycle and income effects are considered, as well as other characteristics including education, employment status and dividend income receipt.

\subsection{Life Cycle Effects}

There is growing interest in how the willingness to take risk varies over the life cycle and whether the life cycle profile is affected by financial crises. Figure 1 provides evidence of an inverse relationship between willingness to take risk and age with older households having lower average elicited risk tolerance than younger households. In this section the aim is to identify the way experienced returns affect the elicited risk

\footnotetext{
${ }^{17} \mathrm{~A}$ formal test of the difference in probabilities between the GFC and the pre-GFC periods is statistically significant for all GFC years when compared to 2006, with the exception of the 2008 GFC period where the change in probability is found to be relatively large but not statistically significant. The results of this test are given in Table A.5 in the Online Appendix.
} 
Table 3: Change in the probabilities of the risk tolerance categories from a decrease in experienced returns from the 90th to the 10th percentile. Based on the Linear model parameter estimates in Table 2 with standard errors in parentheses computed using the delta method.

\begin{tabular}{|c|c|c|c|c|c|c|c|}
\hline \multicolumn{4}{|c|}{ Current Weights } & \multicolumn{4}{|c|}{ Pre-GFC Weights } \\
\hline None & Average & Above & Substantial & None & Average & Above & Substantial \\
\hline $\begin{array}{c}0.013 \\
(0.005)\end{array}$ & $\begin{array}{c}0.007 \\
(0.002)\end{array}$ & $\begin{array}{c}0.002 \\
(0.001)\end{array}$ & $\begin{array}{c}-0.022 \\
(0.008)\end{array}$ & $\begin{array}{c}0.013 \\
(0.005)\end{array}$ & $\begin{array}{c}0.007 \\
(0.002)\end{array}$ & $\begin{array}{c}0.002 \\
(0.001)\end{array}$ & $\begin{array}{c}-0.022 \\
(0.008)\end{array}$ \\
\hline $\begin{array}{l}0.006 \\
(0.004)\end{array}$ & $\begin{array}{c}0.003 \\
(0.002)\end{array}$ & $\begin{array}{c}0.001 \\
(0.001)\end{array}$ & $\begin{array}{l}-0.010 \\
(0.006)\end{array}$ & $\begin{array}{c}0.006 \\
(0.004)\end{array}$ & $\begin{array}{c}0.003 \\
(0.002)\end{array}$ & $\begin{array}{c}0.001 \\
(0.001)\end{array}$ & $\begin{array}{l}-0.010 \\
(0.006)\end{array}$ \\
\hline $\begin{array}{c}0.002 \\
(0.004)\end{array}$ & $\begin{array}{c}0.001 \\
(0.002)\end{array}$ & $\begin{array}{c}0.000 \\
(0.001)\end{array}$ & $\begin{array}{l}-0.003 \\
(0.007)\end{array}$ & $\begin{array}{c}0.002 \\
(0.004)\end{array}$ & $\begin{array}{c}0.001 \\
(0.002)\end{array}$ & $\begin{array}{c}0.000 \\
(0.001)\end{array}$ & $\begin{array}{l}-0.003 \\
(0.007)\end{array}$ \\
\hline $\begin{array}{c}0.004 \\
(0.002)\end{array}$ & $\begin{array}{c}0.002 \\
(0.001)\end{array}$ & $\begin{array}{c}0.001 \\
(0.000)\end{array}$ & $\begin{array}{l}-0.007 \\
(0.003)\end{array}$ & $\begin{array}{c}0.004 \\
(0.002)\end{array}$ & $\begin{array}{c}0.002 \\
(0.001)\end{array}$ & $\begin{array}{c}0.001 \\
(0.000)\end{array}$ & $\begin{array}{l}-0.007 \\
(0.003)\end{array}$ \\
\hline $\begin{array}{l}0.014 \\
(0.003)\end{array}$ & $\begin{array}{c}0.007 \\
(0.002)\end{array}$ & $\begin{array}{c}0.002 \\
(0.001)\end{array}$ & $\begin{array}{l}-0.023 \\
(0.008)\end{array}$ & $\begin{array}{c}0.014 \\
(0.005)\end{array}$ & $\begin{array}{c}0.007 \\
(0.002)\end{array}$ & $\begin{array}{c}0.002 \\
(0.001)\end{array}$ & $\begin{array}{l}-0.023 \\
(0.008)\end{array}$ \\
\hline $\begin{array}{ll}2008 & 0.010 \\
\text { (pre) } & (0.004)\end{array}$ & $\begin{array}{c}0.006 \\
(0.002)\end{array}$ & $\begin{array}{c}0.002 \\
(0.001)\end{array}$ & $\begin{array}{l}-0.018 \\
(0.006)\end{array}$ & $\begin{array}{c}0.010 \\
(0.004)\end{array}$ & $\begin{array}{c}0.006 \\
(0.002)\end{array}$ & $\begin{array}{c}0.002 \\
(0.001)\end{array}$ & $\begin{array}{l}-0.018 \\
(0.006)\end{array}$ \\
\hline $\begin{array}{ll}2008 & 0.038 \\
(\mathrm{GFC}) & (0.021)\end{array}$ & $\begin{array}{c}0.021 \\
(0.011)\end{array}$ & $\begin{array}{c}0.006 \\
(0.003)\end{array}$ & $\begin{array}{l}-0.065 \\
(0.035)\end{array}$ & $\begin{array}{c}0.010 \\
(0.018)\end{array}$ & $\begin{array}{c}0.006 \\
(0.010)\end{array}$ & $\begin{array}{c}0.002 \\
(0.003)\end{array}$ & $\begin{array}{l}-0.017 \\
(0.030)\end{array}$ \\
\hline $\begin{array}{c}0.033 \\
(0.012)\end{array}$ & $\begin{array}{c}0.017 \\
(0.006)\end{array}$ & $\begin{array}{c}0.005 \\
(0.002)\end{array}$ & $\begin{array}{l}-0.054 \\
(0.019)\end{array}$ & $\begin{array}{c}0.007 \\
(0.019)\end{array}$ & $\begin{array}{c}0.004 \\
(0.011)\end{array}$ & $\begin{array}{c}0.001 \\
(0.003)\end{array}$ & $\begin{array}{l}-0.013 \\
(0.034)\end{array}$ \\
\hline $\begin{array}{c}0.026 \\
(0.009)\end{array}$ & $\begin{array}{c}0.013 \\
(0.005)\end{array}$ & $\begin{array}{c}0.004 \\
(0.001)\end{array}$ & $\begin{array}{l}-0.043 \\
(0.015)\end{array}$ & $\begin{array}{c}0.009 \\
(0.016)\end{array}$ & $\begin{array}{c}0.005 \\
(0.009)\end{array}$ & $\begin{array}{c}0.002 \\
(0.003)\end{array}$ & $\begin{array}{l}-0.016 \\
(0.027)\end{array}$ \\
\hline $\begin{array}{c}0.042 \\
(0.014)\end{array}$ & $\begin{array}{c}0.020 \\
(0.007)\end{array}$ & $\begin{array}{c}0.005 \\
(0.002)\end{array}$ & $\begin{array}{l}-0.068 \\
(0.023)\end{array}$ & $\begin{array}{c}0.018 \\
(0.015)\end{array}$ & $\begin{array}{c}0.010 \\
(0.008)\end{array}$ & $\begin{array}{c}0.003 \\
(0.002)\end{array}$ & $\begin{array}{l}-0.031 \\
(0.026)\end{array}$ \\
\hline $\begin{array}{cc}2013-0.014 \\
& (0.006)\end{array}$ & $\begin{array}{c}0.007 \\
(0.003)\end{array}$ & $\begin{array}{c}0.002 \\
(0.001)\end{array}$ & $\begin{array}{l}-0.023 \\
(0.009)\end{array}$ & $\begin{array}{c}0.011 \\
(0.006)\end{array}$ & $\begin{array}{c}0.006 \\
(0.004)\end{array}$ & $\begin{array}{c}0.002 \\
(0.001)\end{array}$ & $\begin{array}{l}-0.019 \\
(0.011)\end{array}$ \\
\hline $\begin{array}{c}0.006 \\
(0.003)\end{array}$ & $\begin{array}{c}0.003 \\
(0.001)\end{array}$ & $\begin{array}{c}0.001 \\
(0.000)\end{array}$ & $\begin{array}{l}-0.011 \\
(0.004)\end{array}$ & $\begin{array}{c}0.007 \\
(0.003)\end{array}$ & $\begin{array}{c}0.004 \\
(0.002)\end{array}$ & $\begin{array}{c}0.001 \\
(0.000)\end{array}$ & $\begin{array}{l}-0.012 \\
(0.005)\end{array}$ \\
\hline $\begin{array}{c}0.010 \\
(0.004)\end{array}$ & $\begin{array}{c}0.004 \\
(0.002)\end{array}$ & $\begin{array}{c}0.001 \\
(0.000)\end{array}$ & $\begin{array}{l}-0.015 \\
(0.006)\end{array}$ & $\begin{array}{c}0.009 \\
(0.004)\end{array}$ & $\begin{array}{c}0.004 \\
(0.002)\end{array}$ & $\begin{array}{c}0.001 \\
(0.000)\end{array}$ & $\begin{array}{l}-0.014 \\
(0.006)\end{array}$ \\
\hline
\end{tabular}


tolerance of households across the life cycle and how that relationship changes when subjected to financial shocks. To investigate this issue the changes in probabilities presented in Table 3 are decomposed by age, beginning with the youngest group of 25-29 to the oldest group of 70-74. The results are presented in Figure 7 for the no risk tolerance category "None" for selected years: pre-GFC (2006), GFC (2008) and post-GFC (2012).

Inspection of Figure 7 reveals two important features. First, the change in probabilities from a negative shock to experienced returns are relatively uniform across all ages. This result holds for the pre-GFC period, as well as for the GFC and postGFC years. A formal test of the constancy of these probability differences for different ages within each year is obtained by comparing the change in probability for each age group with the sample average for each respective wave. The test statistic is computed as the average of the squared differences scaled by the corresponding standard error. Under the null hypothesis the test statistic is asymptotically normal with zero mean and unit variance. The $p$-values for the 2006, 2008 crisis and 2012 periods are respectively $0.164,0.230$ and $0.124 .^{18}$ These results imply that younger and older households respond similarly to extreme changes in experienced returns. ${ }^{19}$

The second important feature revealed by Figure 7 is that there is an upward shift of the life cycle profiles of the probability differences in 2008 and 2012 from the 2006 level. A formal test of this shift from 2006 to the 2008 crisis period, is obtained by averaging across the differences between the estimates for each of the 10 age groups. Dividing this value by its standard error, computed using the delta method, produces a test statistic that is asymptotically distributed with a standardized normal distribution under the null hypothesis. The value of the test statistic is 1.265 which yields a $p$-value of 0.206 confirming the result in Table A.5 that the increased probability differences observed in the 2008 crisis period are not statistically significantly different from those in 2006. However, repeating the test with 2008 replaced by 2012 yields a test statistic

\footnotetext{
${ }^{18}$ These tests were calculated for all waves and possible risk tolerance responses. All of the $p$-values exceeded 0.10 , leaving the conclusion that younger and older households behave the same way in response to a fall in experienced returns qualitatively unchanged. The full set of results are presented in Table A.6 in the Online Appendix.

${ }^{19}$ This result may initially seem to contradict Figure 1 where a strong inverse life cycle effect between average elicited risk tolerance and age is presented. However, Figure 1 is in terms of the level of risk tolerance by age, whereas in Figure 7 it is the change (in the probability) of risk tolerance across the life cycle that is being presented.
} 


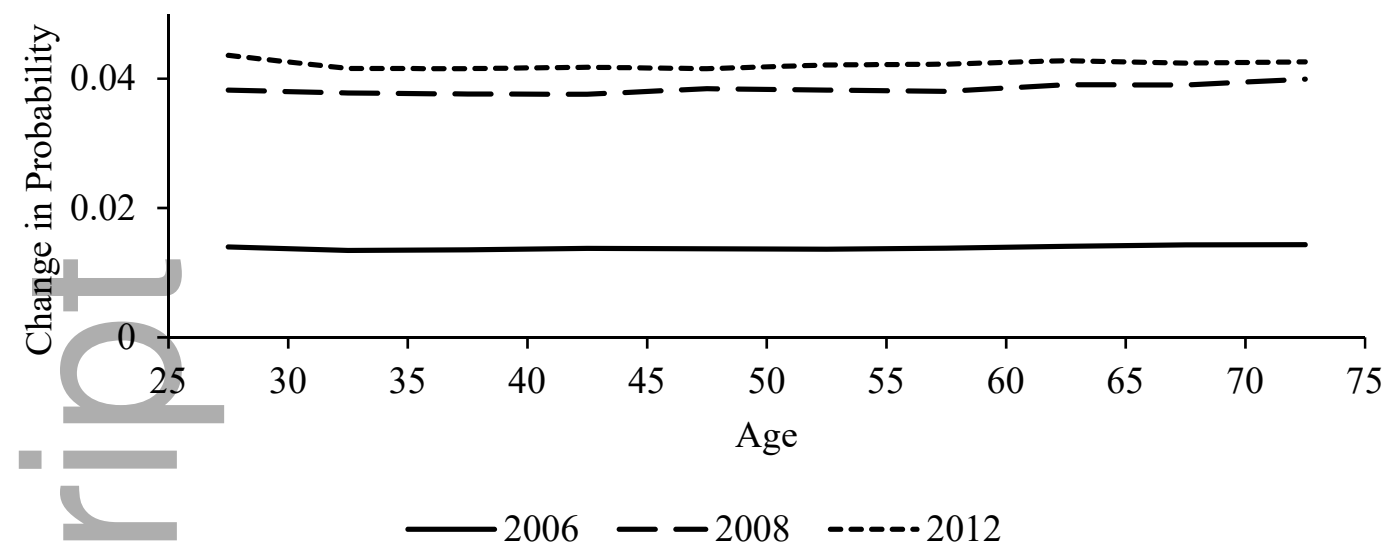

Figure 7: Decomposition by age of the change in probability of the "None" risk tolerance category from a negative shock to experienced returns. Life cycle profiles given for selected years: pre-GFC (2006), GFC (2008), and post-GFC (2012).

of 2.906. The $p$-value is 0.004 , providing strong evidence of a significant uniform shift from 2006 to 2012 in the overall impact of a change in experienced returns (from the 90 th to the 10th percentile) on household willingness to take financial risk across the life cycle.

\subsection{Income Effects}

The results presented in Figure 7 are extended by decomposing the changes in probabilities of each risk tolerance category from a negative shock to experienced returns, by income. The results are presented in Panel A of Table 4 for selected years around the time of the GFC: pre-GFC (2006), GFC (2008) and post-GFC (2012). Three income groups are presented consisting of the lowest incomes ( $0 \%$ to 10\%), middle income earners ( $40 \%$ to $50 \%$ ) and the highest incomes (90\% to 100\%).

Panel A of Table 4 reveals a strong income effect with upper and lower income earners-responding differently to a negative financial shock. For all income groups there is a shift away from the "Substantial" to a lower risk tolerance category, with the difference being that the lower income group tends to shed all risk by shifting into the "None" risk tolerance category, whereas the upper income group tends to still accept some level of risk by spreading the downward shift in willingness to take risk between the "None" and "Average" risk tolerance categories. This difference between upper and lower income earners is sustained during pre-GFC and GFC periods, with the effects being amplified during the latter. In 2006, the change in probability from a negative 
Table 4: Decompositions in terms of household characteristics for selected years from a decrease in experienced returns from the $90 t h$ to the $10 t h$ percentile. The 2008 year consists of households interviewed on or after September 26 of that year. Panel A compares 1st, 5th and 10th income deciles. Panel B compares those with less than high school $(<$ Yr 12), high school (Yr 12) and university (Uni.) education. Panel C compares the unemployed (Unemp.), employed (Emp.) and those not in the labour force (Not). Panel D compares those with (Yes) and without (No) dividend income. Probability differences based on the Linear model parameter estimates in Table 2 with standard errors in parentheses computed using the delta method, where $* * *$, $* *$ and * denote significance at the $1 \%, 5 \%$ and $10 \%$ levels respectively.

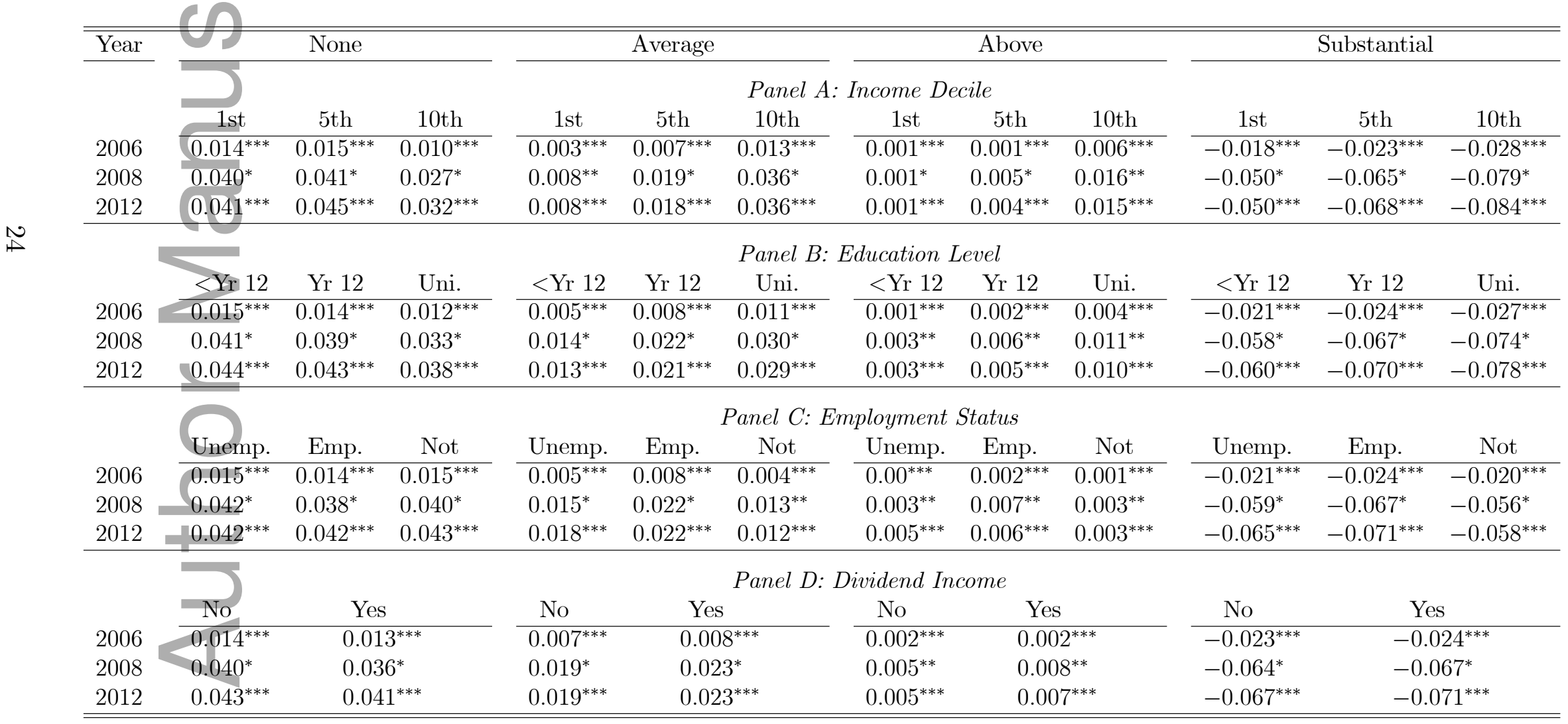

This article is protected by copyright. All rights reserved 
shock for a household in the lowest income group is $-1.8 \%$ ("Substantial") and $1.4 \%$ ("None"), with very little change in the other risk tolerance categories. In contrast, the change in the probabilities for a household in the highest income category are $-2.8 \%$ ("Substantial"), which is roughly evenly spread between the "None" and "Average" risk tolerance categories. In 2012 the changes in probability for the lowest income group are $-5.0 \%$ ("Substantial") and 4.1\% ("None"), whereas for the highest income group the changes are $-8.4 \%$ ("Substantial") which is also approximately evenly spread between the lowest two risk tolerance categories.

\subsection{Other Effects}

Panel B of Table 4 decomposes the change in probability from a negative shock to experienced returns by education. Three levels are considered, ranging from less than 12 years of education ("< Yr 12") to completed high school ("Yr 12") to the highest level of completed university qualification ("Uni."). The results provide no strong evidence the changes in probabilities of each risk tolerance category vary by education. At best, there is weak evidence that changes in elicited risk tolerance for households with different levels of education tend to mimic the income patterns identified in Panel A of Table 4. For example, during the crisis period in 2012, households with lower levels of education tend to switch from the "Substantial" (-6.0\%) to the "None" (4.4\%) risk tolerance categories. In contrast, households with university education tend to switch from the "Substantial" (-7.8\%) risk tolerance category to the lower category "None" $(3.8 \%)$ as well as the "Average" risk tolerance category $(2.9 \%)$.

The results from decomposing probability changes by employment status are given in Panel C of Table 4. Employment status is divided into three categories: unemployed ("Unemp."), employed ("Emp.") and not in the labour force ("Not"). Inspection of the results suggest no significant differences in risk tolerance behaviour between these three groups.

The final decomposition relates to dividend income and is presented in Panel D of Table 4 where the changes in probabilities of households with income from dividends ("Yes") are compared to those without dividend income ("No"). As with the results for education and employment status, there appears to be no strong difference in risk tolerance behaviour between these two groups of households. 


\section{Robustness: Stock Market Volatility}

Stock market volatility is an important measure of financial risk, with higher volatility reflecting a higher risk environment. Increased stock market movements are incorporated into the model of household willingness to take risk through experienced returns. An alternative approach to capture the effects of relatively large movements in stock returns on elicited risk tolerance is to augment the model with an explicit measure of stock market volatility.

To investigate the robustness of the estimated model of elicited risk tolerance based on experienced returns, a measure of volatility is constructed and included as an additional covariate. The volatility measure adopted is based on a threshold GARCH model of daily stock returns on the All Ordinaries index for Australia. ${ }^{20}$ This yields a conditional variance that is a weighted average of past squared (demeaned) stock returns with the memory of the process determined by the GARCH parameter in the model. Daily volatility is computed as the square root of the GARCH conditional variance. ${ }^{21}$ For each household in each wave, the conditional volatility is taken either on the day the interview was conducted or, in the case of a weekend or public holiday interview, the closest trading day prior to the date of the interview. This results in a volatility series which is then augmented to the set of explanatory variables in the model estimated.

The estimates of the key parameters of the Linear weighting specification $\left(\delta_{0}, \delta_{1} \neq 0\right)$ of the risk tolerance model containing volatility are provided in Table 5 with the complete set of parameter estimates given in Table A.4 in the Online Appendix. The key result is that the estimates of the model are robust to the inclusion of volatility as an additional explanatory variable, thereby providing strong support for using experienced returns as a mechanism for explaining elicited risk tolerance. The estimate of

\footnotetext{
${ }^{20}$ Another approach to incorporate volatility into the model could be based on the S\&P ASX200 VIX, implied volatility index. However, data for this series is only available from 2008 onwards and not for the pre-GFC period.

${ }^{21}$ The threshold GARCH model is estimated using daily data from November, 1992 to April, 2019, which are taken from Bloomberg. The estimated model is

$$
\begin{aligned}
r_{t} & =0.0003+\widehat{v}_{t} \\
\widehat{h}_{t} & =1.6 \times 10^{-6}+0.0140 \widehat{v}_{t-1}^{2}+0.1153 \widehat{v}_{t-1}^{2} I_{t-1}+0.9057 \widehat{h}_{t-1}
\end{aligned}
$$

where $r_{t}$ is the stock return, $\widehat{v}_{t}$ is the residual, $\widehat{h}_{t}$ is the estimated GARCH conditional variance, and $I_{t-1}$ is an indicator function that is 1 for $\widehat{v}_{t-1}<0.0$, and 0 otherwise.
} 
Table 5: Maximum likelihood parameter estimates and QMLE standard errors (se) of the elicited risk tolerance model with stock market volatility included. Based on a sample size of $N=51950$. Results are presented for the Linear model $\left(\delta_{0}, \delta_{1} \neq 0, \delta_{2}=0\right)$.

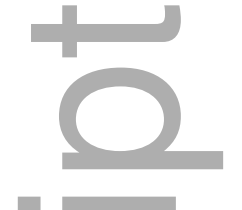

$-$ 0

\begin{tabular}{ccc}
\hline \hline Parameter/Variable & Estimate & $s e$ \\
\hline$\alpha$ & 5.549 & 0.651 \\
Volatility & 1.954 & 1.980 \\
$\beta$ & 3.319 & 0.893 \\
$\phi_{\text {pre }}$ & 1.930 & 0.440 \\
$\delta_{0}$ & 17.364 & 4.534 \\
$\delta_{1}$ & -2.420 & 0.684 \\
$c_{1}$ & 1.534 & 0.009 \\
$c_{2}$ & 2.413 & 0.015 \\
$\log L$ & -0.961336 \\
\hline \hline
\end{tabular}

the parameter $\beta$ for the Linear model in Table 2 is 3.262, which is very similar to the estimate of 3.319 obtained for the model including volatility. Estimates for the experienced returns parameters $\phi_{\text {pre }}, \delta_{0}$ and $\delta_{1}$ are also qualitatively unchanged. Moreover, the parameter estimate on volatility is 1.954, showing a positive relationship between volatility and risk tolerance, but this estimate is nonetheless statistically insignificant with a $p$-value of 0.324 . The importance of stock market volatility is also considered in Malmendier and Nagel (2011) where experienced volatility is included in the model. Consistent with the alternative approach adopted here, they find (i) a positive relationship between volatility and elicited risk tolerance though it is statistically insignificant; and (ii) the estimates on experienced returns are qualitatively unchanged.

\section{Conclusions}

We have studied the effects of the Global Financial Crisis (GFC) on the willingness of households to take financial risk by specifying and estimating a model of elicited risk tolerance using panel data on Australian households from 2001 to 2015. The key feature of the model is an allowance for past real stock returns to influence household risk tolerance. This involves weighting past stock returns over the life of a household, 
referred to as experienced returns by Malmendier and Nagel (2011). To allow for the effects of the GFC on household risk taking behaviour, the weights are allowed to change during the GFC and post-GFC periods.

The empirical results provide strong evidence that households become more myopic during the GFC by placing greater weight on more recent stock returns. Households are found to be more sensitive to large decreases in experienced returns (from the 90th to the 10th percentile) during the GFC when the change in probability of each risk response more than tripled in absolute terms compared to pre-GFC levels; this change is $-6.8 \%$ in 2012 for the "substantial" risk tolerance category compared to $-2.3 \%$ in 2006 . These changes in probabilities revert back to near pre-GFC levels by 2015. The empirical results also show that whilst older households are found to be on average relatively less willing to take financial risk than younger households, the way large changes in experienced returns affects household risk tolerance during the GFC and post-GFC periods tends to be uniform across the life cycle. The empirical results also reveal some differences in how high and low income earners respond to the GFC, however other factors including education, employment status and dividend income, have no significant impact on changes in household risk tolerance.

An important implication of the empirical results was that differences in the willingness to take risk reported in the literature for different countries using the same model, can be reconciled. In particular, a comparison of the results for the U.S. reported by Malmendier and Nagel (2011) and the results for Europe reported by Ampudia and Ehrmann (2017) suggest that European households are relatively more myopic than U.S. households. However, the empirical analysis of the present paper suggests that part of this difference may be the result of the impact of the GFC upon elicited risk tolerance through changes in the way experienced returns were formulated, and the fact that the U.S. results were based solely on pre-GFC data whereas the European results were based on data collected between 2008 and 2010.

The empirical results capturing changes in the relationship between experienced returns and household risk tolerance in response to financial shocks presented here have important implications for economic outcomes such as capital formation and growth, and the efficacy of macroeconomic and retirement saving policies. For policy makers seeking to respond to financial crises, increased myopia of households during financial 
crises essentially changes the underlying behavioural parameters of the policy problem. Reduced household tolerance for financial risk arising with large financial downturns may require policy makers to implement larger fiscal and monetary stimuli than would be anticipated if based on precrisis parameters. This has been the experience across the world in the post-GFC period with unprecedented monetary policies in place.

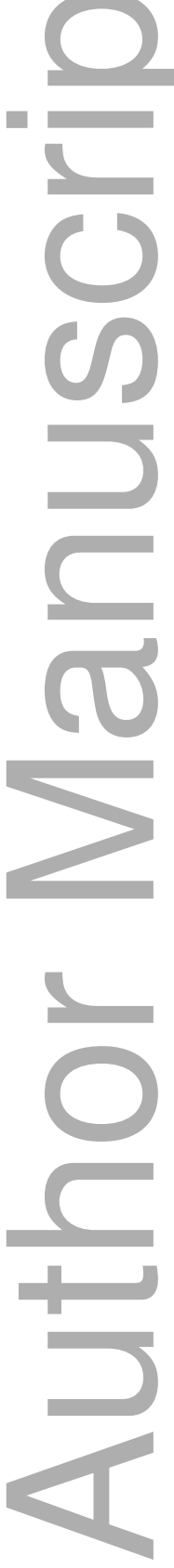




\section{References}

[1] Almon, S., (1965), "The distributed lag between capital appropriations and expenditures", Econometrica 33(1), 178-196.

[2] Ampudia, M., and Ehrmann, M., (2017), "Macroeconomic experiences and risk taking of euro area households", European Economic Review 91, 146-156.

[3] Andreou, E., Ghysels, E., and Kourtellos, A., (2010), "Regression models with mixed sampling frequencies", Journal of Econometrics 158(2), 246-261.

[4] Bali, T.G., and Engle, R.F., (2010), "The intertemporal capital asset pricing model with dynamic conditional correlations", Journal of Monetary Economics 57(4), $377-390$.

[5] Barsky, R.B., Juster, F.T., Kimball, M.S., and Shapiro, M.D., (1997), "Preference parameters and behavioral heterogeneity: An experimental approach in the health and retirement study", The Quarterly Journal of Economics 112(2), 537-579.

[6] Bekaert, G., and Hoerova, M., (2016), "What do asset prices have to say about risk appetite and uncertainty?", Journal of Banking and Finance 67, 103-118.

[7] Bloomberg (2008), "The Sky Falls on Wall Street", https://www.bloomberg.com/news/articles/2008-10-11/the-sky-falls-on-wallstreetbusinessweek-business-news-stock-market-and-financial-advice

[8] Brown, J. R., Martinsson, G., and Petersen, B. C., (2013), "Law, stock markets, and innovation", The Journal of Finance 68(4), 1517-1549.

[9] Brunnermeier, M.K., and Nagel, S., (2008), "Do wealth fluctuations generate timevarying risk aversion? Micro-evidence on individuals' asset allocation", The American Economic Review 98(3), 713-736.

[10] Campbell, J.Y., Cochrane, J., (1999), "By force of habit: A Consumption-based explanation of aggregate stock market behaviour", Journal of Political Economy 107(2), 205-251. 
[11] Cardak, B. A., Martin, V. L., and McAllister, R., (2019), "The effects of the Global Financial Crisis on the stock holding decisions of Australian households", The North American Journal of Economics and Finance 50.

[12] Cohn, A., Engelmann, J., Fehr, E. and Maréchal, M.A., (2015), "Evidence for countercyclical risk aversion: An experiment with financial professionals", American Economic Review 105(2), 860-85.

[13] Dohmen, T., Falk, A., Golsteyn, B., Huffman, D. and Sunde, U., (2017), "Risk attitudes across the life course", Economic Journal, 127, F95-F116.

[14] Dohmen, T., Falk, A., Huffman, D., Sunde, U., Schupp, J., \& Wagner, G. G., (2011), "Individual risk attitudes: Measurement, determinants, and behavioral consequences", Journal of the European Economic Association 9(3), 522-550.

[15] Dungey, M., Matei, M., Luciani, M., \& Veredas, D., (2017), "Surfing through the GFC: Systemic risk in Australia", Economic Record 93(300), 1-19.

[16] Engle, R.F., Ghysels, E., and Sohn, B., (2013), "Stock market volatility and macroeconomic fundamentals", The Review of Economics and Statistics 95(3), $776-797$.

[17] Frijters, P., Johnston, D. W., Shields, M. A., \& Sinha, K., (2015), "A lifecycle perspective of stock market performance and wellbeing", Journal of Economic Behavior and Organization 112, 237-250.

[18] Guiso, L., and Paiella, M., (2008), "Risk aversion, wealth, and background risk", Journal of the European Economic Association 6(6), 1109-1150.

[19] Guiso, L., Sapienza P., and Zingales, L., (2018), "Time varying risk aversion", Journal of Financial Economics, forthcoming.

[20] Heckman, J., and Robb, R., (1985), "Using longitudinal data to estimate age, period and cohort effects in earnings equations", In Cohort analysis in social research (pp. 137-150). Springer, New York, NY. 
[21] Hoffmann, A. O., Post, T., and Pennings, J. M., (2013), "Individual investor perceptions and behavior during the financial crisis", Journal of Banking and Finance 37(1), 60-74.

[22] Hutchinson, D., and Ploeckl, F., (2018), "What was the Australian GDP or CPI then?", MeasuringWorth, URL: http://www.measuringworth.com/australiadata/

[23] IMF, (2009), World economic outlook: Crisis and recovery, Washington, DC: International Monetary Fund.

[24] Kandasamy, N., Hardy, B., Page, L., Schaffner, M., Graggaber, J., Powlson, A.S., Fletcher, P.C., Gurnell, M. and Coates, J., (2014), "Cortisol shifts financial risk preferences", Proceedings of the National Academy of Sciences of the United States of America 111 (9), 3608-3613.

[25] Malmendier, U. and Nagel, S., (2011), "Depression babies: Do macroeconomic experiences affect risk taking?", Quarterly Journal of Economics 126(1), 373-416.

[26] Merkle,C., and Weber, M., (2014), "Do investors put their money where their mouth is? Stock market expectations and investing behavior", Journal of Banking and Finance 46, 372-386.

[27] Miller, S. M., (2014), "Risk-Sharing, Vulnerability and the Global Financial Crisis", Economic Record 90(289), 220-235.

[28] Sahm, C.R., (2012), "How much does risk tolerance change?" The Quarterly Journal of Finance 2(04), 1250020.

[29] Summerfield, M., Freidin, S., Hahn, M., Li, N., Macalalad, N., Mundy, L, Watson, N., Wilkins, R. and Wooden, M., (2015), "HILDA User Manual - Release 14", Melbourne Institute of Applied Economic and Social Research, University of Melbourne.

[30] Weber, M., Weber, E. U., and Nosić, A., (2013), "Who takes risks when and why: Determinants of changes in investor risk taking", Review of Finance 17(3), $847-883$. 


\section{A Online Appendix: Additional Data and Results}

\section{A.1 Summary Statistics}

Table A.1: Summary statistics of control variables used in estimation of model for all households $(N=51950)$. Currency units are real Australian dollars (base year 2010).

\begin{tabular}{|c|c|c|c|c|c|}
\hline Variable & 10th pct & Median & 90th pct & Mean & $\mathrm{SD}$ \\
\hline Elicited risk tolerance & 1 & 2 & 3 & 1.729 & 0.724 \\
\hline Income (\$ 000’s) & 25.683 & 81.168 & 179.116 & 97.895 & 84.962 \\
\hline Education (University) & 0 & 0 & 1 & 0.288 & 0.453 \\
\hline Education (High school) & 0 & 0 & 1 & 0.239 & 0.426 \\
\hline English speaking ${ }^{(a)}$ & 0 & 1 & 1 & 0.885 & 0.319 \\
\hline Retired & 0 & 0 & 1 & 0.156 & 0.363 \\
\hline Female & 0 & 0 & 1 & 0.192 & 0.394 \\
\hline Married & 0 & 1 & 1 & 0.682 & 0.466 \\
\hline Dependent children & 0 & 0 & 1 & 0.160 & 0.460 \\
\hline & 30 & 48 & 67 & 48.510 & 13.400 \\
\hline W01 & 0 & 0 & 0 & 0.080 & 0.271 \\
\hline W02 & 0 & 0 & 0 & 0.074 & 0.262 \\
\hline W03 & 0 & 0 & 0 & 0.074 & 0.261 \\
\hline W04 & 0 & 0 & 0 & 0.074 & 0.262 \\
\hline W06 & 0 & 0 & 0 & 0.071 & 0.258 \\
\hline W08 & 0 & 0 & 0 & 0.069 & 0.254 \\
\hline W10 & 0 & 0 & 0 & 0.075 & 0.263 \\
\hline W11 & 0 & 0 & 0 & 0.092 & 0.290 \\
\hline W12 & 0 & 0 & 0 & 0.097 & 0.295 \\
\hline $\mathrm{W} 13$ & 0 & 0 & 0 & 0.096 & 0.295 \\
\hline W14 & 0 & 0 & 0 & 0.099 & 0.299 \\
\hline W15 & 0 & 0 & 0 & 0.099 & 0.298 \\
\hline
\end{tabular}

(a) English speaking includes Australian born and immigrants from English speaking countries. 


\section{A.2 Australian Stock Index Returns Data}

The HILDA survey household level data are complemented with macroeconomic data on historical stock returns and inflation taken from Hutchinson and Ploeckl (2018). As part of the Measuring Worth project, they construct a long term (1875-present) Australian stock index (the All Ordinaries index) and inflation series. Comprehensive details on the sources and methods used for the construction of these series are provided in Hutchinson and Ploeckl (2018). As the oldest household head in the sample is 74 in 2001, the earliest relevant returns correspond to 1928, given returns are taken from the first year after birth. The time series of 1920-2015 real returns, expressed as a percentage, is presented in Figure A.1. An important feature of the Hutchinson and Ploeckl (2018) data is the timing: computations are for Australian financial (or tax) years which end on 30 June. Financial year stock returns fit well with the survey questions on household willingness to take financial risk which are largely collected between August and November of each year; more than 90\% of survey responses are collected in this window each year with none collected before 30 June. As a result, experienced returns $\left(a_{i t}\right)$ are computed using returns experienced in the financial year immediately preceding the collection of these data; e.g. for willingness to take risk in 2006, the most recent return used in the calculation of $a_{i 2006}$ is the return for the financial year ending 30 June 2006.

The main negative shocks for the empirical analysis are the GFC in 2008, with real returns for the years ending 30 June 2008 and 2009 of $-16.71 \%$ and $-29.69 \%$ respectively, and the European debt crisis in 2012 with a real return for the year ending 30 June 2012 of $-11.31 \%$.

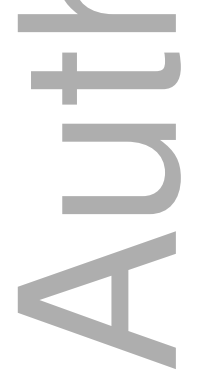

This article is protected by copyright. AH4rights reserved 


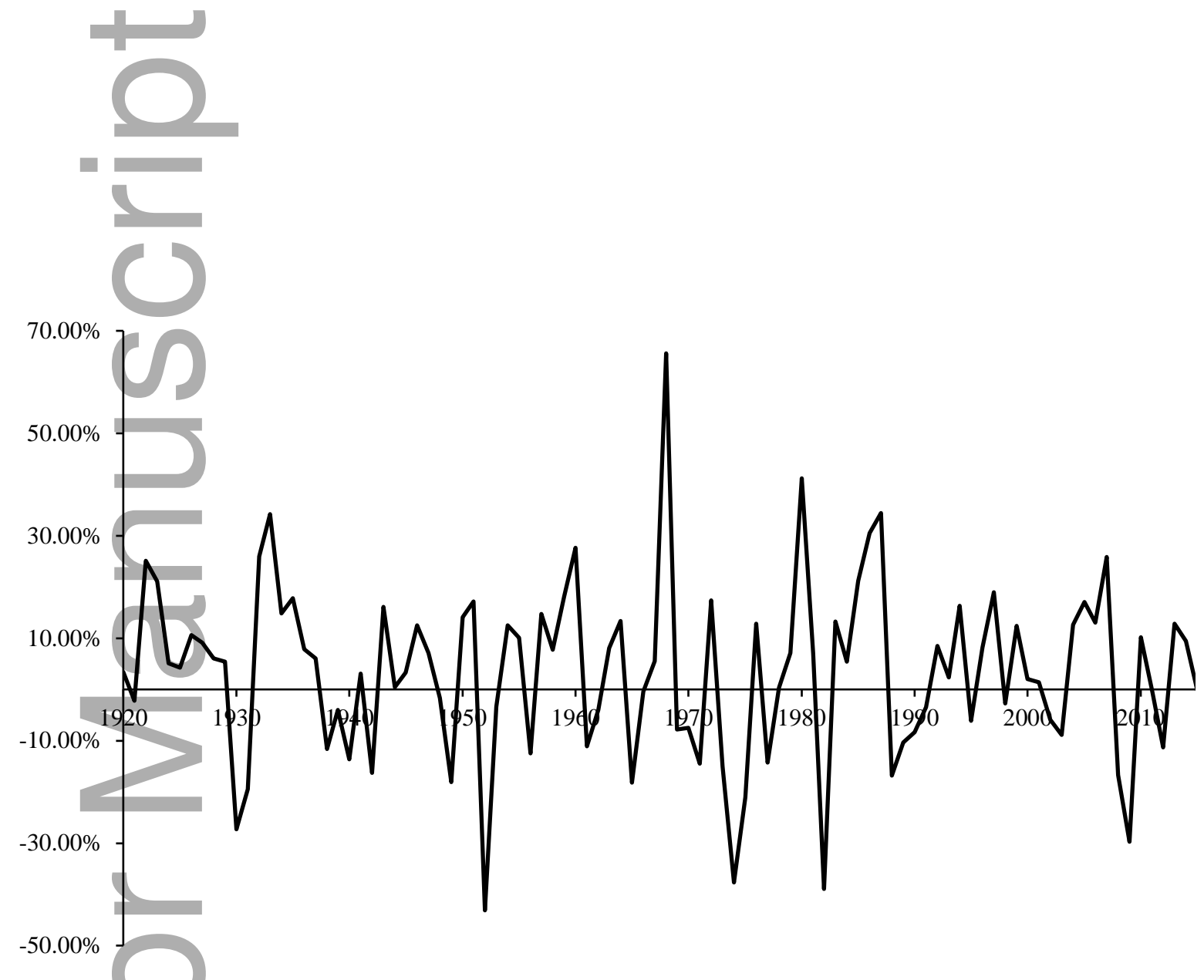

Figure A.1: Time series of percentage annual real stock returns for Australia, based on financial years (July-June), 1920-2015.

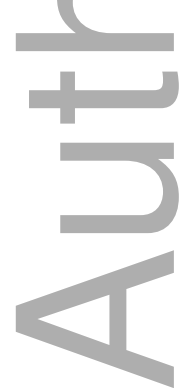




\section{A.3 Full Results of Estimated Models}

Table A.2: Maximum likelihood parameter estimates and QMLE standard errors (se) of the elicited risk tolerance model. Based on a sample size of $N=51950$. Columns $(1),(2),(3)$ and $(4)$ contain the Quadratic $\left(\delta_{0}, \delta_{1}, \delta_{2} \neq 0\right)$, Linear $\left(\delta_{0}, \delta_{1} \neq 0, \delta_{2}=0\right)$, Step $\left(\delta_{0} \neq 0, \delta_{1}=\delta_{2}=0\right)$ and Fixed $\left(\delta_{0}=\delta_{1}=\delta_{2}=0\right)$ models respectively.

\begin{tabular}{|c|c|c|c|c|c|c|c|c|}
\hline \multirow{2}{*}{ Parameter/Variable } & \multicolumn{2}{|c|}{ Quadratic } & \multicolumn{2}{|c|}{ Linear } & \multicolumn{2}{|c|}{ Step } & \multicolumn{2}{|c|}{ Fixed } \\
\hline & Estimate & se & Estimate & se & Estimate & $s e$ & Estimate & $s e$ \\
\hline Constant $(\alpha)$ & 5.560 & 0.653 & 5.571 & 0.653 & 5.555 & 0.653 & 5.514 & 0.653 \\
\hline $\log$ (income) & -1.430 & 0.116 & -1.430 & 0.116 & -1.429 & 0.117 & -1.423 & 0.116 \\
\hline $\log$ (income) squared & 0.080 & 0.005 & 0.080 & 0.005 & 0.080 & 0.005 & 0.079 & 0.005 \\
\hline Education (University) & 0.489 & 0.013 & 0.489 & 0.013 & 0.489 & 0.013 & 0.489 & 0.013 \\
\hline Education (High School) & 0.265 & 0.014 & 0.266 & 0.014 & 0.265 & 0.014 & 0.265 & 0.014 \\
\hline English speaking $^{(a)}$ & 0.153 & 0.017 & 0.153 & 0.017 & 0.153 & 0.017 & 0.153 & 0.017 \\
\hline Retired & -0.067 & 0.020 & -0.066 & 0.019 & -0.066 & 0.019 & -0.063 & 0.018 \\
\hline Femal & 0.483 & 0.018 & 0.483 & 0.018 & 0.483 & 0.018 & 0.483 & 0.018 \\
\hline Married & -0.122 & 0.016 & -0.122 & 0.016 & -0.121 & 0.016 & -0.121 & 0.016 \\
\hline Dependent children & -0.029 & 0.011 & -0.029 & 0.011 & -0.029 & 0.011 & -0.030 & 0.011 \\
\hline Age $(/ 100)$ & -0.036 & 0.080 & -0.045 & 0.060 & -0.022 & 0.054 & -0.023 & 0.053 \\
\hline 2002 & 0.011 & 0.027 & 0.010 & 0.029 & 0.009 & 0.026 & 0.018 & 0.029 \\
\hline 2003 & 0.034 & 0.029 & 0.032 & 0.034 & 0.031 & 0.031 & 0.048 & 0.038 \\
\hline 2004 & 0.002 & 0.027 & 0.002 & 0.032 & 0.001 & 0.027 & 0.011 & 0.031 \\
\hline 2006 & -0.080 & 0.027 & -0.079 & 0.027 & -0.078 & 0.027 & -0.084 & 0.028 \\
\hline 2008 & -0.066 & 0.034 & -0.063 & 0.030 & -0.080 & 0.027 & -0.075 & 0.027 \\
\hline 2010 & 0.030 & 0.065 & 0.012 & 0.067 & -0.071 & 0.038 & -0.090 & 0.036 \\
\hline 2011 & 0.019 & 0.066 & -0.001 & 0.061 & -0.059 & 0.039 & -0.078 & 0.038 \\
\hline 2012 & 0.056 & 0.122 & 0.018 & 0.079 & -0.046 & 0.055 & -0.081 & 0.053 \\
\hline 2013 & -0.025 & 0.042 & -0.036 & 0.047 & -0.049 & 0.038 & -0.061 & 0.041 \\
\hline 2014 & -0.059 & 0.029 & -0.063 & 0.035 & -0.064 & 0.031 & -0.063 & 0.035 \\
\hline 2015 & -0.199 & 0.033 & -0.195 & 0.036 & -0.183 & 0.033 & -0.185 & 0.038 \\
\hline$\beta$ & 3.408 & 0.889 & 3.262 & 1.095 & 3.144 & 1.134 & 3.264 & 1.415 \\
\hline$\phi_{\text {pre }}$ & 1.925 & 0.450 & 1.951 & 0.475 & 1.975 & 0.432 & 2.899 & 0.432 \\
\hline$\delta_{0}$ & 14.850 & 6.500 & 15.586 & 4.357 & 3.307 & 2.079 & 0.000 & \\
\hline$\delta_{1}$ & -0.434 & 6.922 & -2.154 & 0.655 & 0.000 & & 0.000 & \\
\hline$\delta_{2}$ & -0.242 & 0.910 & 0.000 & & 0.000 & & 0.000 & \\
\hline$c_{1}$ & 1.533 & 0.009 & 1.533 & 0.009 & 1.533 & 0.009 & 1.533 & 0.009 \\
\hline$c_{2}$ & 2.413 & 0.015 & 2.413 & 0.015 & 2.413 & 0.015 & 2.413 & 0.015 \\
\hline $\log L$ & -0.961 & 346 & -0.961 & & -0.9613 & 395 & -0.961 & 126 \\
\hline
\end{tabular}

${ }^{(a)}$ English speaking includes Australian born and immigrants from English speaking countries. 


\section{A.4 Robustness Results}

Table A.3: Maximum likelihood parameter estimates and QMLE standard errors (se) of robustness test of the elicited risk tolerance model where all 2008 wave observations are treated as GFC observations ( $\phi_{0} \neq 0$ for all 2008 observations). Based on a sample size of $N=51950$. Columns (1), (2), (3) and (4) contain the Quadratic $\left(\delta_{0}, \delta_{1}, \delta_{2} \neq 0\right)$, Linear $\left(\delta_{0}, \delta_{1} \neq 0, \delta_{2}=0\right)$, Step $\left(\delta_{0} \neq 0, \delta_{1}=\delta_{2}=0\right)$ and Fixed $\left(\delta_{0}=\delta_{1}=\delta_{2}=0\right)$ models respectively.

\begin{tabular}{|c|c|c|c|c|c|c|c|c|}
\hline \multirow{2}{*}{ Parameter/Variable } & \multicolumn{2}{|c|}{ Quadratic } & \multicolumn{2}{|c|}{ Linear } & \multicolumn{2}{|c|}{ Step } & \multicolumn{2}{|c|}{ Fixed } \\
\hline & Estimate & se & Estimate & se & Estimate & $s e$ & Estimate & se \\
\hline Constant & 5.598 & 0.650 & 5.599 & 0.650 & 5.554 & 0.652 & 5.518 & 0.654 \\
\hline $\log ($ incor & -1.435 & 0.116 & -1.433 & 0.116 & -1.429 & 0.116 & -1.425 & 0.117 \\
\hline $\log$ (income) squared & 0.080 & 0.005 & 0.080 & 0.005 & 0.080 & 0.005 & 0.079 & 0.005 \\
\hline Education (University) & 0.489 & 0.013 & 0.489 & 0.013 & 0.489 & 0.013 & 0.489 & 0.013 \\
\hline Education (High School) & 0.266 & 0.014 & 0.266 & 0.014 & 0.265 & 0.014 & 0.266 & 0.014 \\
\hline English speaking $^{(a)}$ & 0.153 & 0.017 & 0.153 & 0.017 & 0.153 & 0.017 & 0.153 & 0.017 \\
\hline Retired & -0.066 & 0.018 & -0.066 & 0.018 & -0.066 & 0.019 & -0.063 & 0.019 \\
\hline Female & 0.483 & 0.018 & 0.483 & 0.018 & 0.483 & 0.018 & 0.483 & 0.018 \\
\hline Married & -0.121 & 0.016 & -0.121 & 0.016 & -0.121 & 0.016 & -0.121 & 0.016 \\
\hline Depende & -0.029 & 0.011 & -0.029 & 0.011 & -0.029 & 0.011 & -0.030 & 0.011 \\
\hline Age $(/ 10$ & -0.056 & 0.054 & -0.059 & 0.059 & -0.026 & 0.053 & -0.027 & 0.057 \\
\hline 2002 & 0.011 & 0.026 & 0.009 & 0.028 & 0.010 & 0.027 & 0.019 & 0.029 \\
\hline 2003 & 0.034 & 0.030 & 0.031 & 0.035 & 0.032 & 0.032 & 0.052 & 0.039 \\
\hline 2004 & 0.002 & 0.027 & 0.001 & 0.031 & 0.001 & 0.028 & 0.013 & 0.032 \\
\hline 2006 & -0.079 & 0.027 & -0.078 & 0.027 & -0.079 & 0.027 & -0.085 & 0.028 \\
\hline 2008 & -0.056 & 0.052 & -0.043 & 0.056 & -0.092 & 0.029 & -0.076 & 0.027 \\
\hline 2010 & 0.019 & 0.057 & 0.009 & 0.058 & -0.067 & 0.038 & -0.086 & 0.037 \\
\hline 2011 & 0.008 & 0.053 & -0.004 & 0.054 & -0.055 & 0.040 & -0.074 & 0.040 \\
\hline 2012 & 0.036 & 0.079 & 0.013 & 0.069 & -0.038 & 0.056 & -0.075 & 0.055 \\
\hline 2013 & -0.029 & 0.042 & -0.039 & 0.045 & -0.045 & 0.039 & -0.057 & 0.043 \\
\hline 2014 & -0.060 & 0.030 & -0.064 & 0.035 & -0.061 & 0.032 & -0.059 & 0.036 \\
\hline 2015 & -0.197 & 0.030 & -0.198 & 0.038 & -0.180 & 0.034 & -0.181 & 0.039 \\
\hline$\beta$ & 3.330 & 1.027 & 3.142 & 1.229 & 3.307 & 1.147 & 3.434 & 1.457 \\
\hline$\phi_{\text {pre }}$ & 1.963 & 0.449 & 1.984 & 0.499 & 1.875 & 0.434 & 2.919 & 0.452 \\
\hline$\delta_{0}$ & 14.260 & 6.763 & 16.185 & 7.907 & 3.447 & 1.866 & 0.000 & \\
\hline$\delta_{1}$ & -0.978 & 2.637 & -2.270 & 1.198 & 0.000 & & 0.000 & \\
\hline$\delta_{2}$ & -0.149 & 0.289 & 0.000 & & 0.000 & & 0.000 & \\
\hline$c_{1}$ & 1.533 & 0.009 & 1.533 & 0.009 & 1.533 & 0.009 & 1.533 & 0.009 \\
\hline & 2.413 & 0.015 & 2.413 & 0.015 & 2.413 & 0.015 & 2.413 & 0.015 \\
\hline $\log L$ & -0.961 & 355 & -0.961 & 358 & -0.961 & & -0.961 & \\
\hline
\end{tabular}

${ }^{(a)}$ English speaking includes Australian born and immigrants from English speaking countries. 
Table A.4: Maximum likelihood parameter estimates and QMLE standard errors (se) of the elicited risk tolerance model with stock market volatility included. Based on a sample size of $N=51950$. Results are presented for the Linear model $\left(\delta_{0}, \delta_{1} \neq 0, \delta_{2}=0\right)$.

\begin{tabular}{|lcc}
\hline \multicolumn{1}{c}{ Parameter/Variable } & Estimate & se \\
\hline Constant $(\alpha)$ & 5.549 & 0.651 \\
$\log ($ income) & -1.431 & 0.116 \\
$\log ($ income) squared & 0.080 & 0.005 \\
Education (University) & 0.489 & 0.013 \\
Education (High School) & 0.266 & 0.014 \\
English speaking $(a)$ & 0.153 & 0.017 \\
Retired & -0.066 & 0.018 \\
Female & 0.483 & 0.018 \\
Married & -0.122 & 0.016 \\
Dependent children & -0.029 & 0.011 \\
Age $(/ 100)$ & -0.044 & 0.051 \\
2002 & 0.018 & 0.027 \\
2003 & 0.046 & 0.033 \\
2004 & 0.017 & 0.030 \\
2006 & -0.070 & 0.028 \\
2008 & -0.070 & 0.030 \\
2010 & 0.031 & 0.054 \\
2011 & -0.000 & 0.047 \\
2012 & 0.043 & 0.066 \\
2013 & -0.021 & 0.040 \\
2014 & -0.050 & 0.031 \\
2015 & -0.198 & 0.030 \\
Volatility & 1.954 & 1.980 \\
$\phi_{\text {pre }}$ & 3.319 & 0.893 \\
$\delta_{0}$ & 1.930 & 0.440 \\
$\delta_{1}$ & 17.364 & 4.534 \\
$c_{1}$ & -2.420 & 0.684 \\
$c_{2}$ & 1.534 & 0.009 \\
log $L$ & 2.413 & 0.015 \\
$(a)$ English speaking includes Australian & born and immigrants \\
from English speaking countries. & & \\
& -0.961336 \\
\hline
\end{tabular}




\section{A.5 Additional Testing Results}

Table A.5: Test of a change in the probabilities of the risk categories between the GFC years (2008 to 2015) and the pre-GFC year 2006. Based on the Linear model parameter estimates in Table 2 using current weights, with standard errors in parentheses.

\begin{tabular}{ccccc}
\hline \hline Year & None & Average & Above & Substantial \\
\hline 2008 & 0.024 & 0.013 & 0.004 & -0.042 \\
& $(0.019)$ & $(0.010)$ & $(0.003)$ & $(0.032)$ \\
2010 & 0.019 & 0.009 & 0.003 & -0.031 \\
& $(0.007)$ & $(0.004)$ & $(0.001)$ & $(0.012)$ \\
2011 & 0.012 & 0.006 & 0.002 & -0.019 \\
& $(0.005)$ & $(0.003)$ & $(0.001)$ & $(0.009)$ \\
2012 & 0.028 & 0.013 & 0.003 & -0.045 \\
& $(0.010)$ & $(0.004)$ & $(0.001)$ & $(0.015)$ \\
2013 & 0.000 & 0.000 & 0.000 & 0.000 \\
& $(0.003)$ & $(0.002)$ & $(0.000)$ & $(0.005)$ \\
2014 & -0.008 & -0.004 & -0.001 & 0.013 \\
& $(0.003)$ & $(0.001)$ & $(0.000)$ & $(0.005)$ \\
2015 & -0.004 & -0.003 & -0.001 & 0.008 \\
& $(0.002)$ & $(0.001)$ & $(0.001)$ & $(0.004)$ \\
\hline
\end{tabular}

This article is protected by copyright. Al9rights reserved 


\begin{tabular}{|c|c|c|c|c|}
\hline \multicolumn{5}{|c|}{$\begin{array}{l}\text { Table A.6: Results ( } p \text {-values) of test of constancy for different ages withi } \\
\text { each sample year of the change in the probability of risk tolerance cate } \\
\text { gories from a decrease in experienced returns from the 90th to the } 10 t \\
\text { percentile. The test statistic is computed as the average of the square } \\
\text { differences of the change in probability for each age group from the sam } \\
\text { ple average for each respective wave scaled by the corresponding standarc } \\
\text { error. Based on the Linear model parameter estimates in Table } 2 \text {. }\end{array}$} \\
\hline Year & None & Average & Above & Substantial \\
\hline 2001 & 0.174 & 0.169 & 0.168 & 0.172 \\
\hline 2002 & 0.419 & 0.405 & 0.407 & 0.404 \\
\hline 2003 & 0.823 & 0.825 & 0.825 & 0.826 \\
\hline 2004 & 0.257 & 0.252 & 0.252 & 0.253 \\
\hline 2006 & 0.164 & 0.145 & 0.147 & 0.147 \\
\hline 2008 (pre) & 0.192 & 0.158 & 0.164 & 0.157 \\
\hline 2008 (GFC) & 0.230 & 0.357 & 0.337 & 0.378 \\
\hline 2010 & 0.187 & 0.173 & 0.173 & 0.176 \\
\hline 2011 & 0.186 & 0.185 & 0.185 & 0.188 \\
\hline 2012 & 0.124 & 0.152 & 0.150 & 0.159 \\
\hline 2013 & 0.238 & 0.241 & 0.240 & 0.244 \\
\hline 2014 & 0.238 & 0.241 & 0.240 & 0.243 \\
\hline 2015 & 0.178 & 0.200 & 0.198 & 0.203 \\
\hline
\end{tabular}




\section{University Library}

\section{- M M N E R VA A gateway to Melbourne's research publications}

Minerva Access is the Institutional Repository of The University of Melbourne

Author/s:

Cardak, BA;Martin, VL

Title:

Once in a Lifetime? The Effects of the Global Financial Crisis on Household Willingness to Take Financial Risk

Date:

2019-11-06

Citation:

Cardak, B. A. \& Martin, V. L. (2019). Once in a Lifetime? The Effects of the Global Financial Crisis on Household Willingness to Take Financial Risk. The Economic Record, 95 (311), pp.442-461. https://doi.org/10.1111/1475-4932.12506.

Persistent Link:

http://hdl.handle.net/11343/286928 